C2020. Licensed under the Creative Commons Attribution-NonCommercial-NoDerivatives 4.0 International http://creativecommons.org/about/downloads

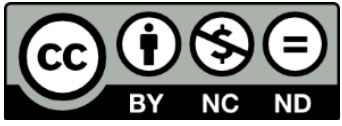

Accepted for publication in Journal of Pharmaceutical Sciences and can be found at https://doi.org/10.1016/j.xphs.2020.08.029 


\title{
3D printing of solid oral dosage forms: numerous challenges with unique opportunities
}

\author{
Ogochukwu Lilian Okafor-Muo ${ }^{1}$, Hany Hassanin², Reem Kayyali' ${ }^{1}$, Amr ElShaer ${ }^{1}$ * \\ ${ }^{1}$ Drug Discovery, Delivery and Patient Care (DDDPC) Theme, School of Life Sciences, Pharmacy and \\ Chemistry, Department of Pharmacy, Kingston University London, Kingston upon Thames, Surrey, KT1 $2 \mathrm{EE}$ \\ ${ }^{2}$ School of Engineering, the University of Canterbury Christ Church, Canterbury, CT1 1QU
}

*Corresponding authors:

Dr Amr Elshaer

Drug Discovery, Delivery and Patient Care (DDDPC) Theme

School of Life Sciences, Pharmacy and Chemistry

Kingston University London

Penrhyn Road, Kingston upon Thames,

Surrey, KT1 2EE, UK

Email: a.elshaer@kingston.ac.uk

T +44 (0)20 84177416 (Internal: 67416)

\section{ABSTRACT}

Since the FDA approval of Spritam, there has been a growing interest in the application of 3D printing in pharmaceutical science. 3D printing is a method of manufacturing involving the layer-by-layer deposition of materials to create a final product according to a digital model. There are various techniques used to achieve this method of printing including the SLS, SLA, FDM, SSE and PB-inkjet printing. In biomanufacturing, bone and tissue engineering involving $3 D$ printing to create scaffolds, while in pharmaceutics, 3D printing was applied in drug development, and the fabrication of drug delivery devices. This paper aims to review the use of some 3D printing techniques in the fabrication of oral solid dosage forms. FDM , SLA SLS, and PB-Inkjet printing processes were found suitable for the fabrication of oral solid dosage forms, though a great deal of the available research was focused on fused deposition modelling due to its availability and flexibility. Process parameters as well as strategies to control the characteristics of printed dosage forms are analysed and discussed. The review also presents the advantages and possible limitations of 3D printing of medicines. 


\section{List of Abbreviations}

3D, 3-Dimensional; $A B S$, acrylonitrile butadiene styrene; $A M$, additive manufacturing; $C A D$, computer aided design; CIJ, continuous inkjet; DDD, drug delivery device; DoD-Drop on Demand; DPPO, diphenyl(2,4,6-trimethylbenzoyl) phosphine oxide; DSC, differential scanning calorimetry; EIJ, electrostatic inkjet; FDA-Food and Drug Administration; FDM, fused deposition modelling; FTIR, fourier transform infrared spectrophotometry; HME, hot melt extrusion; HPC, hydroxypropyl cellulose; HPMC, hydroxypropyl methyl cellulose; MB, Methylene Blue; PB, Powder bed; PCL, poly capro lactone; PEG, polyethylene glycol; PEGDA, polyethylene glycol diacrylate; PEGDMA, polyethylene glycol dimethacrylate; pHEMA, poly-2-hydroxyethyl methacrylate; PLA, polylactic acid; PLLA, poly (I) lactic acid; PPF-DEF, polypropylene fumarate-diethyl fumarate; PVA, polyvinyl alcohol; PVP, polyvinylpyrrolidone; SSE, semisolid extrusion; SLA, stereolithography; SLS, selective laser sintering; TEC, triethyl citrate; TGA, thermogravimetric analysis; W, Watts.

\section{Table of Contents}

ABSTRACT...

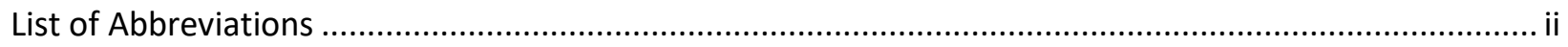

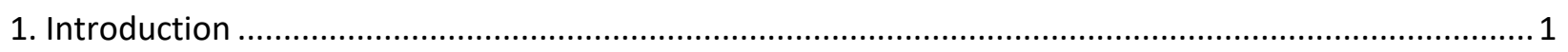

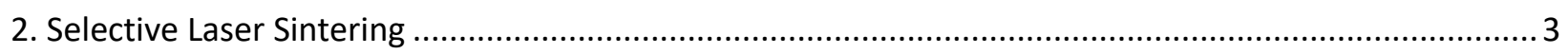

2.1. Materials used for Selective Laser Sintering ........................................................................... 4

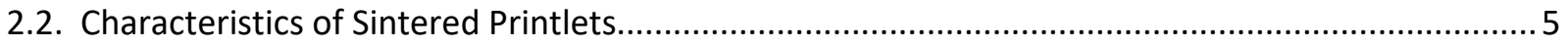

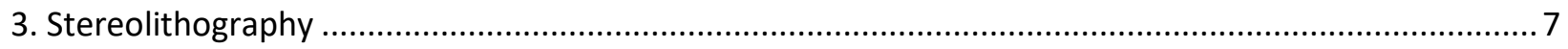

3.1. Photopolymerisable Materials for Stereolithography ….......................................................... 8

3.2. Characteristics and Drug Release Properties of SLA Printlets ................................................... 9

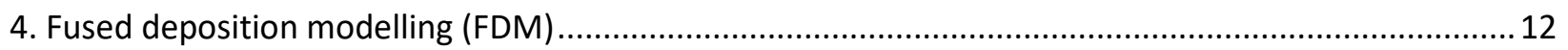

4.1 Polymer Filaments for Fused Deposition Modelling ................................................................ 13

4.2. Incorporating APIs into Polymer Filaments for 3D Printing ..................................................... 16

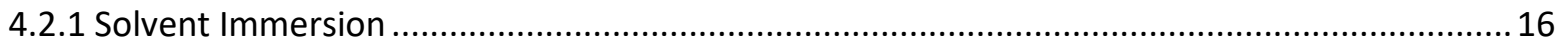

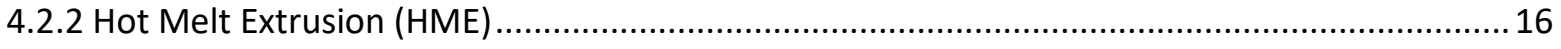

4.3 Printing and extrusion parameters for FDM filaments ................................................................ 17

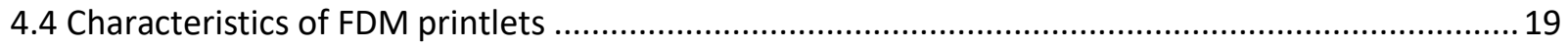

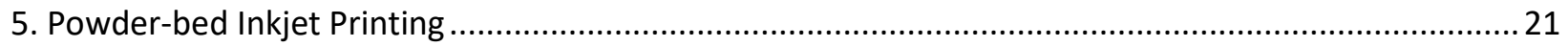

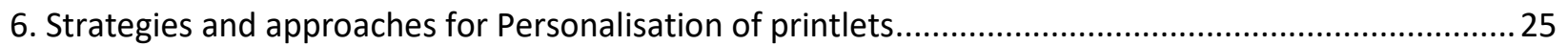




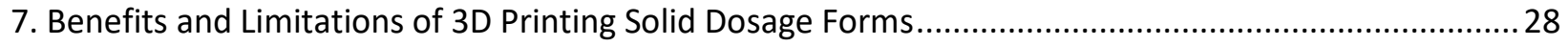

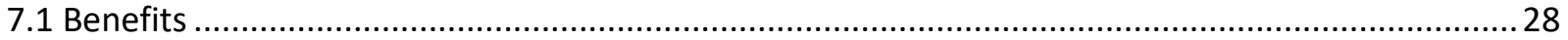

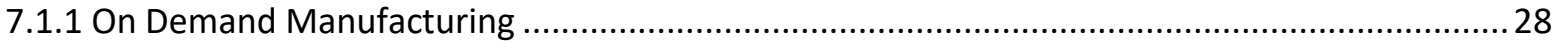

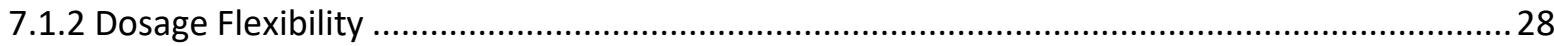

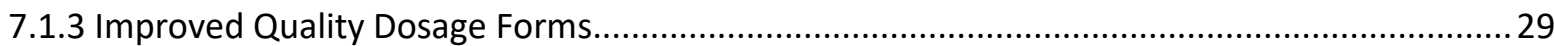

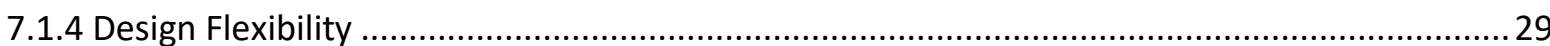

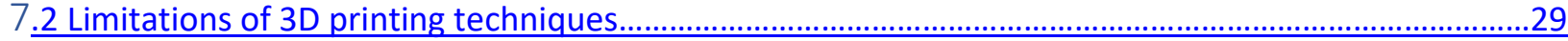

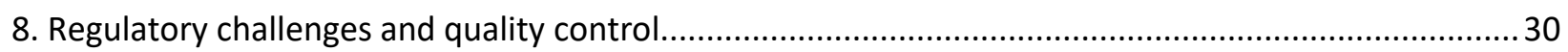

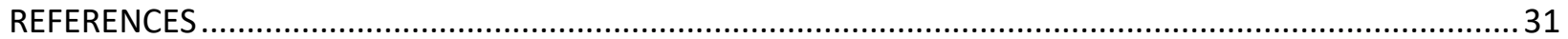




\section{Introduction}

Although not a new concept, 3D printing or additive manufacturing has discovered a wide range of uses in various industries. It is a technique using solid free form fabrication that has found useful applications, such as in satellite and jet engines (1), unmanned aerial vehicles (2), sensors (3), tailor-made implants (1) (2) and scaffolds (3) (4) for patients in need of bone or tissue regeneration. 3D printing has been used to produce prosthetics, medical devices, and artificial organs $(5)(4,6)$. In recent years, 3D printing has generated growing interest in the pharmaceutical field where it has been used to fabricate different drug delivery systems and dosage forms, which have been referred to in recent reports as printlets Formatting... please wait (7) (8) (9). Oral solid dosage forms are the most commonly used forms of medications not only because they are simple to manufacture and have nearly accurate dosing, but also due to their easy and painless administration that can be achieved without the need for a health care professional (10). Oral solid dosage forms therefore generate good adherence and compliance hence good patient outcome. 3D printing of oral dosage forms has been widely investigated in pharmaceutical manufacturing (11).

3D printing is based on the layer-by-layer concept in the fabrication of objects, which are digitally designed. The technology was able to process wide range of materials such as polymers (12), ceramics (13), metals (14-18), wood (19) and organic tissue (20). 3D objects can also be generated from the predefined transformation of smart materials in response to external stimuli through a process, which has come to be referred to as 4D printing. External stimuli such as heat, $\mathrm{pH}$, light or magnetic field could be used to cause transformations such as changes in geometry and function to give programmable materials (21). 3D printing provides novel advantages compared to traditional pharmaceutical processes that involve powder preparation, milling, blending, granulation, and compression (22), which lack manufacturing flexibility and process capability. It also brings many possibilities for pharmaceutics, such as production of personalized, complex and made-on-demand products (23). The working principle of most 3D printing technologies are very similar. First, the product design, geometry and part sizes are generated using a CAD software, converted into a machine-readable format and sliced into printable layers. Raw materials are processed into powder, filaments, or binder solutions to be deposited in a layerby-layer system to create the physical objects. Finally, certain products may require some form of postprocessing treatment usually involving the removal of support or excess materials. Drug product manufacturing makes use of several 3D printed methods depending on raw material, equipment, and solidification process (24). Some 3D printing technologies in Table 1 and have been used by the 
pharmaceutical industry. This paper presents an extensive review on the use of 3D printing technologies for the fabrication of oral solid dosage forms using SLS, SLA, FDM, and PB inkjet printing techniques. The general processing concept, potentials, and challenges of each 3D printing tool is analysed and discussed.

Table 1: 3D printing techniques used for the fabrication of oral medicines

\begin{tabular}{|c|c|c|c|}
\hline 3D Printing technique & $\begin{array}{l}\text { Consolidation } \\
\text { source }\end{array}$ & Material form & Basic consolidation mechanism \\
\hline Selective Laser Sintering & $\begin{array}{l}\text { Laser beam } \\
\text { e.g. } \mathrm{CO}_{2} \text { Laser }\end{array}$ & Powders & $\begin{array}{l}\text { Powder is deposited in successive } \\
\text { layers on a build platform and fully } \\
\text { or partially melted with the aid of a } \\
\text { laser beam. (25). }\end{array}$ \\
\hline Stereolithography & UV beam & Resins & $\begin{array}{l}\text { Photocurable liquid resins are } \\
\text { polymerized by focusing of a UV } \\
\text { beam on designated paths to cure } \\
\text { the selected resin areas by } \\
\text { crosslinking (26) }\end{array}$ \\
\hline Fused Deposition Modelling & Heated nozzle & Filaments & $\begin{array}{l}\text { Thermoplastic polymer filaments } \\
\text { are passed through a heated nozzle } \\
\text { to produce melted polymer matrix } \\
\text { which is deposited in layers onto a } \\
\text { build platform (27) }\end{array}$ \\
\hline Powder bed-Inkjet & $\begin{array}{l}\text { Binder/thermal } \\
\text { energy }\end{array}$ & Powders & $\begin{array}{l}\text { Layers of materials, usually powder } \\
\text { are deposited onto a build plate and } \\
\text { subsequently consolidated using a } \\
\text { binder solution often referred to as } \\
\text { ink (28) }\end{array}$ \\
\hline
\end{tabular}




\section{Selective Laser Sintering (SLS)}

SLS is a 3D printing technology whereby a laser beam is used to fuse particles of powder layer-by-layer (Figure 1). Similar to all powder bed 3D printing processes, the concept of selective laser sintering is based on the spread of layers of powder of 0.05 to $0.3 \mathrm{~mm}$ thickness followed by the selective laser beam scanning of each layer (29). The sintered powder creates the part or final structure, whereas the unsintered excess acts as the support structure, which is removed by post-printing processing (30). SLS has many advantages since it is a one-step process. Moreover, the use of additives to bind the object replaces the use of the laser, which also provides higher resolution due to low wavelength, making it not only cost effective but also eco-friendly and time efficient. However, the high temperature of the process due to the laser's energy may cause the degradation of the active ingredient within the powder (31) (32) Formatting... please wait.

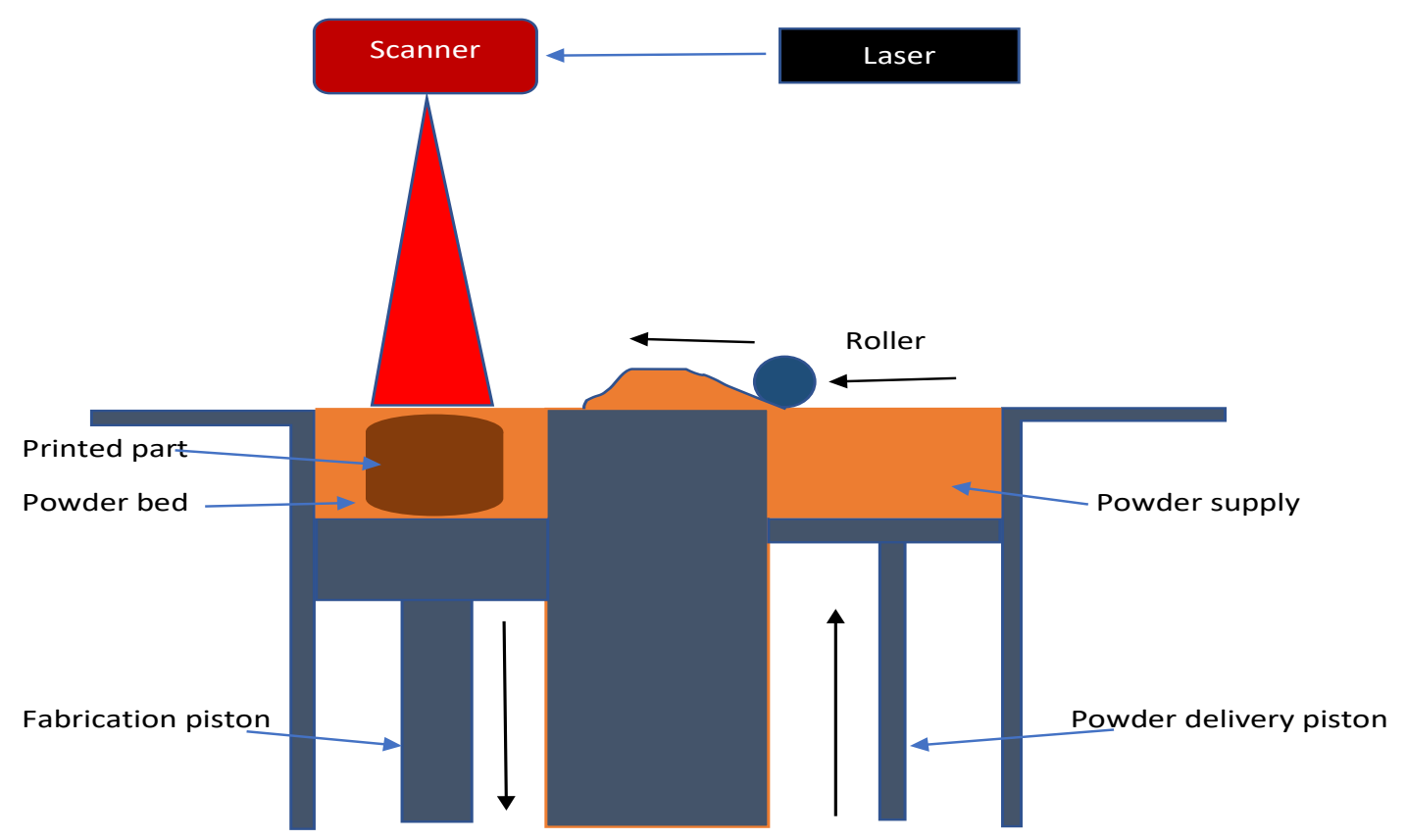

Figure 1: - Schematic diagram of selective laser sintering showing the different parts of SLS including powder roller, laser beam source, laser scanner and fabrication piston. 


\subsection{Materials used for Selective Laser Sintering}

The starting materials used in SLS must be in form of powder with suitable flow characteristics to allow easy deposition of thin layers. The particle size of powder is typically below $180 \mu \mathrm{m}$ (33). SLS processes a wide range of materials including ceramics, polymers, metal, and alloys. The process has shown that it cannot only be used to process powder mixed with a low melting temperature material, which can serve as a binder, but also has the ability to cause sintering without the need of a binder (14). The sintering mechanisms that occurs in selective laser sintering depend on the material used and the desired mechanical properties. These mechanisms include solid state sintering used to process ceramic and metallic powders and liquid phase sintering used in composite materials (34). Polymers such as polyamide, polystyrene, and polycarbonate are the most widely processed materials in SLS (35) (29)

Factors such as bioavailability, biodegradability and biocompatibility of the powder are of great importance in the field of biomedical and pharmaceutical sciences. Two biodegradable thermoplastic polymers PCL and PLLA were studied by Leong et al (36), for the fabrication of controlled release tablets. The PLLA powder used in this study would not sinter at a low laser power and led the researchers to increase laser power until sintering occurred at $12 \mathrm{~W}$. A study by Fina et al (31), demonstrated the use of Kollicoat and Eudragit polymers to formulate tablets because of their pharmaceutical characteristics as well as their immediate and modified release profile. The authors used Candurin Gold Sheen mixed with the two materials to help in the printing process. It was shown that, although the laser beam had no degradation effect on the Kollicoat/Eudragit-paracetamol powder blends, the addition of Candurin Gold sheen to the mixture improved absorption of the laser energy to improve the print ability. Other pharmaceutical grade polymers explored include Kollidon and HPMC (9). A Summary of different materials processed by SLS for the manufacturing of oral dosage forms is in Table 2 .

Table 2: - Summary of different polymers used in manufacturing of oral dosage forms using SLS

\begin{tabular}{|l|l|l|l|}
\hline Polymer & Active ingredient & Material(s) added & Printing temperature $\left({ }^{\circ} \mathbf{C}\right)$ \\
\hline Kollicoat IR (31) & Paracetamol & Candurin ${ }^{\circledR}$ Gold Sheen & $90-110$ \\
\hline Eudragit L100-55 (31) & Paracetamol & Candurin ${ }^{\circledR}$ Gold Sheen & $90-110$ \\
\hline Polyethylene Oxide (7) & Paracetamol & Candurin ${ }^{\circledast}$ Gold Sheen & $35-50$ \\
\hline Ethyl Cellulose (7) & Paracetamol & Candurin $^{\circledR}$ Gold Sheen & $100-120$ \\
\hline Eudragit RL (7) & Paracetamol & Candurin $^{\circledR}$ Gold Sheen & $65-85$ \\
\hline HPMC (9) & Paracetamol & Candurin $^{\circledast}$ Gold Sheen & $115-135$ \\
\hline
\end{tabular}




\begin{tabular}{|l|l|l|l|}
\hline Kollidon$^{\circledast}(9)$ & Paracetamol & Candurin $^{\circledR}$ Gold Sheen & $80-100$ \\
\hline Polycaprolactone (36) & Methylene Blue & & 40 \\
\hline Poly lactic acid (36) & Methylene Blue & & 60 \\
\hline
\end{tabular}

\subsection{Characteristics of Sintered Printlets}

Studies carried out on SLS are mostly geared towards engineering applications while development in the area of biomedical science especially tissue engineering or production of DDDs has been less significant. To design an SLS printed dosage form, it is important to identify significant parameters, as there are several variable process parameters involved in selective laser sintering relating to the powder mean diameter, size distribution, density, layer thickness, binder ratio fraction, and the laser scan speed, power, spot size and absorbed energy (25). The identification of significant parameters and the effect of their interaction is necessary for process optimization. Properties of sintered parts affected by printing variables include porosity, yield strength, hardness, surface roughness, and layer thickness. Leong et al (36) investigated the influence of three critical parameters; laser power, laser scan speed, and part bed temperature on creating dense wall formation and porous infill of biomedical materials. These parameters were used to control the porosity of SLS printed circular discs made for controlled drug delivery by zeroorder release. The objective was to create a disc with two concentric circular regions of varying porosity; dense outer region for barrier effect and a porous inner region for drug encapsulation. The study used powder blends from two biodegradable thermoplastic polymers; PCL and PLLA while Methylene Blue (MB) used as a model drug. The results showed that the increase in bed temperature and laser power led to a decrease in porosity, while increase in scan speed led to an increase in porosity. After the optimization process to obtain porosity above $50 \%$, the parameters chosen for PLLA disc were $60^{\circ} \mathrm{C}$ part bed temperature, $1270 \mathrm{~mm} / \mathrm{s}$ scan speed and $12 \mathrm{~W}$ laser power as no sintering was observed on PLLA powder at the laser power of $11 \mathrm{~W}$ and below. For the $\mathrm{PCL}$ disc, $40^{\circ} \mathrm{C}$ bed temperature, $5080 \mathrm{~mm} / \mathrm{s}$ scan speed and $4 \mathrm{~W}$ and $3 \mathrm{~W}$ laser power for outer and inner regions respectively were preferred. The final built samples evaluated by TGA, DSC and FTIR showed sintering of SLS did not affect the PCL-MB characteristics, properties or chemical composition. Thus, it was concluded that this technique has the potential to manufacture promising devices for drug delivery and that controlling printing variables is essential to control the properties of the printed parts. The above study reported no drug release studies of the DDD, however in order to control the rate of release of the device, concentric rings separated from a wall were 
created to act as diffusion obstacles. This approach was expected to prevent the so-called 'initial burst', characterised by the release of more than the desired drug concentration when the device is placed in a medium for the first time.

The first report on the use of SLS in the preparation of drug dosage forms for oral use was in 2017 and explored the drug release properties of printed tablets (31). The study investigated the feasibility of employing SLS printing for the fabrication of solid oral medicines using thermoplastic polymers. For this purpose, Kollicoat IR and Eudragit L100-55 polymers were selected and separately mixed with 5, 20 and $35 \% \mathrm{w} / \mathrm{w}$ paracetamol resulting in six final formulations to be printed into tablets. The measured porosity of printed tablets showed that while Kollicoat porosity was similar for all drug loading, Eudragit porosity seemed to reduce with increased drug load. SEM images showed more sintered/melted areas were generated within the printlets with increase in drug loading suggesting that the increase in drug content produced more sintering of particles and less porous tablets (Figure 2).

(a)

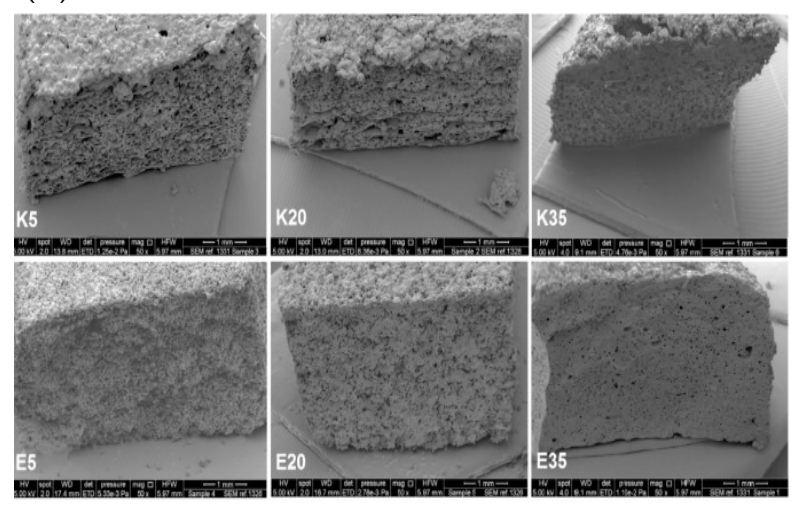

(b)

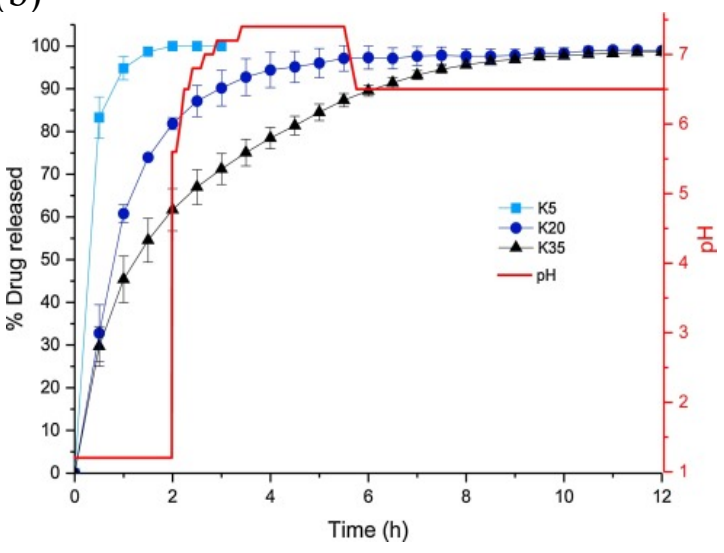

Figure 2: (a) SEM images of vertical sections of Kollicoat printlets (top) and Eudragit printlets (bottom) showing the effect of increasing drug load (left to right) on the porosity of printlets (b) drug dissolution profiles from Kollicoat printlets at 5, 20 and 35\% drug loading (K5,K20 and K35) (31) Formatting...

please wait

An important consideration in the assessment of feasibility of fabrication of dosage form by SLS printing is the effect of laser beams on drug stability. No sign of significant degradation among the printlets was found as evidenced by the high percentage drug loading similar to the theoretical drug loading and the presence of only paracetamol peak on the HPLC chromatogram. The printed tablets also showed low friability values (below 1\%) making them compliant with the pharmacopeia standard. Additionally, 
dissolution tests were run for the six formulations. In the case of Kollicoat, complete and faster drug release was reached in 2 hours for the formulation with 5\% paracetamol in comparison with the 10 hours required to dissolve the formulations with $20 \%$ and $35 \%$ paracetamol. Fina et al provided basis for SLS to being a promising tool, opening the door for this technology to be further researched in relation to the pharmaceutical field and its potential to produce personalized medicines (31). Developments in the form of fabricating tablets with enhanced drug release characteristics was published again by Fina et al. in a study that aimed to produce orally disintegrating tablets. HPMC E5 and Kollidon ${ }^{\circledR}$ VA 64 were used to create oral solid dosage forms combined separately with $5 \%$ of paracetamol. Different scanning speeds $(100 \mathrm{~mm} / \mathrm{s} ; 200 \mathrm{~mm} / \mathrm{s} ; 300 \mathrm{~mm} / \mathrm{s})$ were studied on their effect to modify release characteristics of the 3D printed tablets and the results seemed to confirm the inverse relationship between laser scan speed and porosity as well as their effect on drug release (36). At a scanning speed of $100 \mathrm{~mm} / \mathrm{s}$, particles were partially fused together whereas when the speed was increased, particles were mostly loose. Moreover, HPMC particles fabricated at $100 \mathrm{~mm} / \mathrm{s}, 200 \mathrm{~mm} / \mathrm{s}$ and $300 \mathrm{~mm} / \mathrm{s}$ showed complete dissolution rates at 4, 3 and 2 hours respectively. Kollidon tablets presented faster dissolution times, $60 \mathrm{~min}$ and $10 \mathrm{~min}$, depending on the laser speed. As a conclusion, the study suggests that increasing the laser scanning leads to a reduction of particles sintering and consequently, a higher overall porosity, which facilitates dissolution (9)

\section{Stereolithography}

Stereolithography is a 3D printing method that involves the layer-by-layer solidification via polymerization of liquid resin by a light beam (Figure 3). An ultraviolet or other light source when focused on a tank filled with a photosensitive resin causes crosslinking and forms a polymeric matrix (24). The platform is lowered after the curing of each layer and a new layer of uncured polymer resin is deposited on thetop of the cured layer for the next curing in a bottom-to-top build approach, see Figure 3. An alternative approach involves the curing of resin layer through a transparent plate in the bottom of the resin tray by a light source from below. After each layer curing, the platform is raised, and uncured resin is allowed to fill the space between the platform and plate allowing subsequent layers to be cured in a top-down approach. During crosslinking reaction of resins, the power of the light source, speed of scanning and the quantity of monomer and photoinitiator determine the kinetics, which in turn influence the thickness of cured layer as well as the time of curing (37). Advantages of this printing method include high resolution and speed of printing (38), as well as reduced localized heating making it suitable for the printing of thermolabile drugs (26). In addition, the high-resolution capabilities of stereolithography enabled the 
technique to be used in the fabrication of microneedles patches with high quality similar to those fabricated microfabrication techniques such as soft lithography (39), though it was originally used to fabricate Nano and Micro patterns for micro electro mechanical systems (39-48).

Another advantage relevant in the field of pharmaceutics is that this method of printing allows the incorporation of miscible materials such as excipients and APIs which may not be polymerisable to be entrapped in the polymeric matrix upon crosslinking (26) (49)

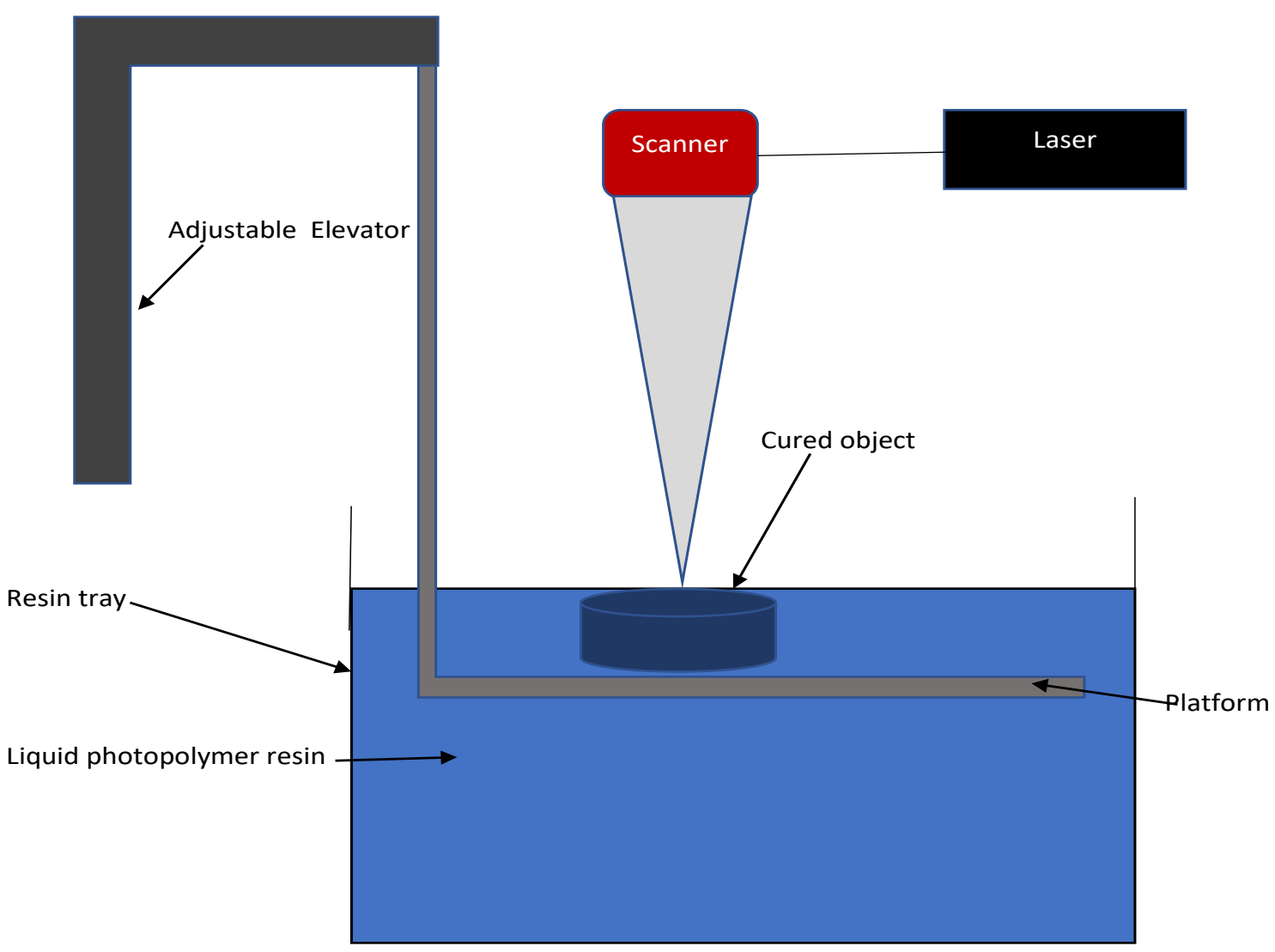

Figure 3: - Schematic representation of stereolithography showing different parts of 3D printer including laser/UV source, resin tray and printing platform.

\subsection{Photopolymerisable Materials for Stereolithography}

Stereolithography requires the use of photopolymerisable materials, which are not very common in pharmaceutical manufacturing. Over the years, a number of photopolymerisable materials have been 
developed such as PEGDA, pHEMA, PEGDMA and PPF/DEF (49). Hydrogels on the other hand are 3D polymer networks that have been well applied in tissue regeneration and engineering due to their high water content. They have diffusive and mechanical characteristics that are adjustable, influenced by the extent of crosslinking, making them ideal in drug delivery applications (50). Photopolymerisation of hydrogels has been explored extensively in terms of materials and methods and this has led to the synthesis of several biocompatible hydrogels of various characteristics. Like PEGDA, alternative bases of these hydrogels may include 2-(diisopropylamino)ethyl methacrylate, chitosan derivatives or gelatinchondroitin sulphate and hyaluronic acid (51). As a result, stereolithographic 3D printing was used in tissue engineering and scaffolding and has also recently been used to produce microparticles. There have only been a few studies on the use of stereolithography in drug delivery, most of which employ PEGDA as the polymer of choice for printing. Although hydrogels have proven to be very applicable in the design of drug delivery systems with controlled release.

Other than the photopolymerisable resins, another material, a photoinitiator is also required to trigger polymerization on exposure to light by transforming to reactive radicals (52) (53) Formatting... please wait. There are concerns about the potential toxicity of uncured resins that may contain high concentration of these radicals with several researchers stating concerns (24). For example, the fabrication of a photoinitiator-free PEGDA scaffold using mask projected excimer laser SLA 3D printing method (54). The scaffold demonstrated better biocompatibility than photoinitiator-containing scaffolds by showing no release of toxic chemicals during cell proliferation test. Other studies aimed at improving biocompatibility include the use of biobased unsaturated polyesters and soybean oil epoxidized acrylate as well as photoinitiators from natural compounds such as riboflavin (55) (56) (57) (58).

\subsection{Characteristics and Drug Release Properties of SLA Printlets}

In 2014, Vehse et al (28) fabricated a drug loaded PEGDA scaffolds using diode laser curing. For this study, the photopolymerisation initiator DPPO was used to aid the process and the parameters; laser power, scan speed and hatch distance were optimized prior to printing. The UV-resistant antiplatelet drug, acetylsalicylic acid was mixed with the resin and the strength and drug delivery characteristics of the scaffold were analysed. Different concentrations of the drug could be successfully incorporated into the scaffold, which was able to release $95 \%$ of the drug within 3 hours. The compressive strength of the scaffold however reduced with increased drug concentration showing that the drug interfered with curing. Ibuprofen loaded hydrogels also based on PEGDA were fabricated by Martinez et al in a study that investigated feasibility of producing pre-wetted hydrogels with the same SLA printing technology. This 
took advantage of the ability of crosslinking to entrap the non-photopolymerisable water component within the matrix, allowing for the production of moist drug loaded hydrogels. The formulations contained DPPO as the photoinitiator, however produced printlets with irregular shape and led to the replacement of the potentially toxic DPPO polymer with a safer and more pharmaceutically used Riboflavintriethanolamine combination. Hydrogels comprising mainly of PEGDA displayed excessive brittleness leading to the addition of PEG 300 to the formulation to create a plasticizing effect and reduce brittleness. Drug release was dependent on water content, as higher water content produced faster drug release. It was concluded that SLA 3DP is a suitable way to create drug loaded hydrogels, suggesting potential for use in pharmaceutical manufacturing (51).

One of the first SLA printed dosage forms for oral use was the printlet fabricated with PEGDA by Wang et al (15) who explored the feasibility of producing drug loaded tablets with modified-release profiles (Figure 4). PEGDA and PEG 300 were the primary materials used for this study as photopolymerisable polymer and plasticizer respectively in different ratios to prepare the photo-reactive solutions, while 4aminosalicylic acid (4-ASA) and paracetamol were selected as model drugs. Drug concentration in the photopolymer solution and 3D tablets was determined by HPLC showing no significant difference in drug loading between the formulations and theoretical drug loading. Unlike the scaffolds from Vehse et al (51), drug release did not depend on the $\mathrm{pH}$ of the media but on the concentration of the polymer in the photopolymer solution. This may be due to the difference in polymer composition and design of formulation between the two studies. This study also showed that the level of crosslinking determined by the ratio of PEGDA, affects the rate of drug release. Low percentages of PEGDA displayed a faster drug release as formulations with 35\% PEGDA released $100 \%$ of paracetamol within 10 hours due to less crosslinking, whereas formulations containing $65 \%$ and $90 \%$ PEGDA showed $84 \%$ and $76 \%$ drug release in the same amount of time, respectively (26). 


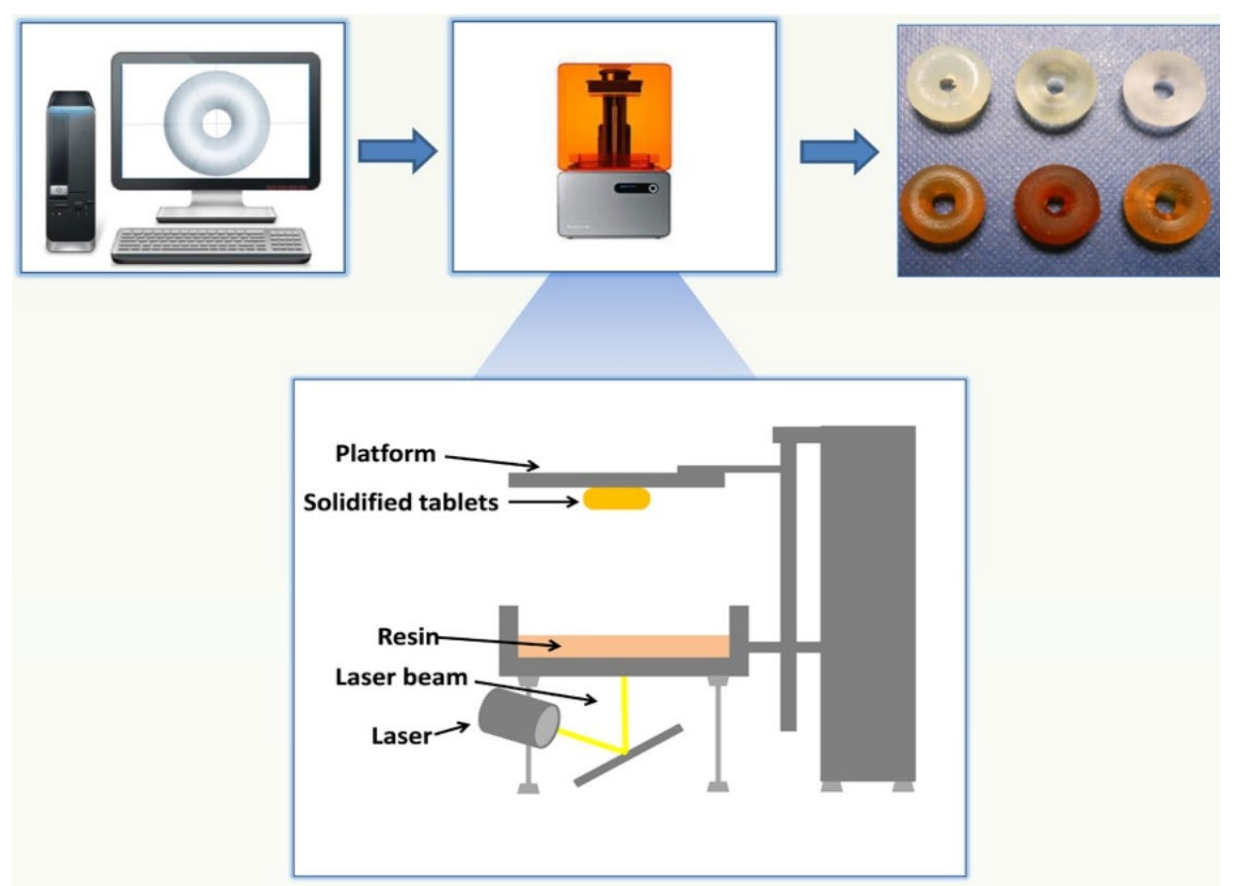

Figure 4: Schematic representation of using SLA to print drug loaded tablets with examples of some SLA 3D printed tablets (15).

SLA printlets produced by Martinez et al (59) also used PEGDA resin and paracetamol as the model drug. The photoinitiator used was diphenyl(2,4,6-trimethylbenzoyl) 76 phosphine oxide (TPO). Printlets were successfully printed with high resolution and crosslinking density. The drug content determination showed approximately $3.82 \%$ of paracetamol content out of the $4 \%$ that was loaded. The printlets also had physical dimensions close to the designed dimension. Printlets dimensions for the cylindrical and ringshaped polypills formulated in another study by Martinez et al produced a different result, yielding wider diameters than targeted. This was possibly due to the printer settings or the liquid formulation (60). The attempted use of SLA in the printing of polypills, (Figure 5) have also met with some limitations, including diffusion of components between layers of polypills(39) as well as possible drug-polymer interaction (61). 

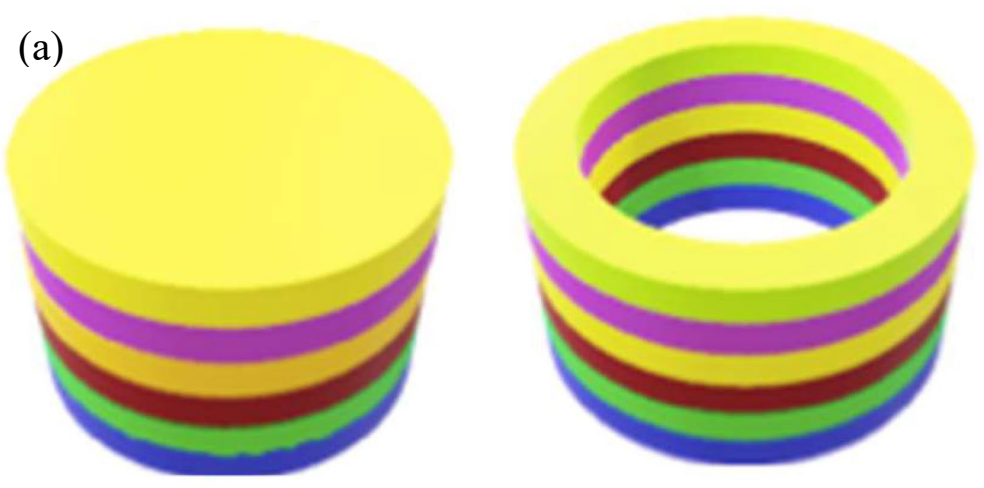

Naproxen

Aspirin

Paracetamol

Caffeine

Chloramphenicol

Prednisolone
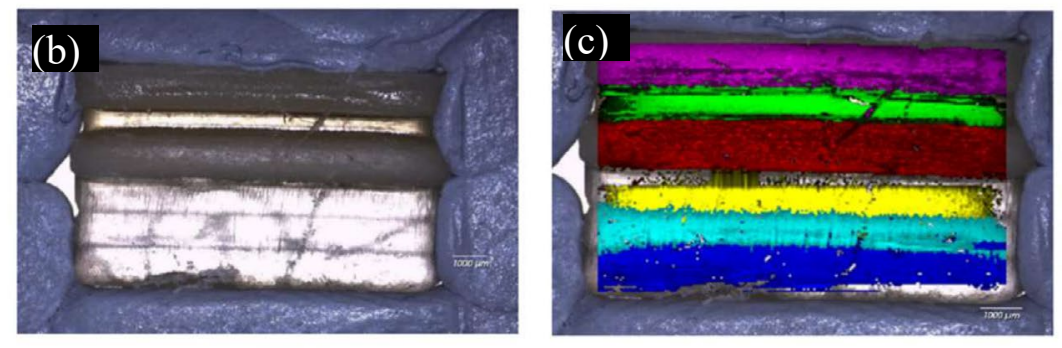

Prednisolone layer

Chloramphenicol layer

Caffeine layer

Paracetamol layer

Aspirin layer

Naproxen layer

Figure 5: (a) Schematic representation of the proposed SLA cylindrical and ring-shaped polypills, (b) optical light microscopy imaging and (c) Raman mapping of cylindrical SLA polypill showing the different drugs' layers; prednisolone, chloramphenicol, caffeine, paracetamol, aspirin and naproxen (60)

\section{Formatting... please wait}

\section{Fused deposition modelling (FDM)}

FDM is a method of 3D printing that involves the layer-by-layer deposition of a molten polymer onto a platform to create a 3D object. The deposition of building material is by the feeding of a polymer filament into the heated printer-head and nozzle of the 3D printer. Heating into a melted semi-solid form extruded onto the printer platform occurs. The nozzle extrudes the polymer along $x$ and $y$-axis to form a layer and the stage lowered to accommodate the next layer. Hence the material build up along z-axis (Figure 6). The geometry and size of the printed material is designed with the aid of CAD software. Common challenges avoided are excess residual solvent occurring in inkjet printing by using fused deposition modelling as a printing technique. Despite the many advantages of this method in terms of its simplicity, cheap cost and easy accessibility (62), it has limitations such as thermal degradation of ingredients, slow drug dissolution speed and poor drug loading (63) (64). 


\subsection{Polymer Filaments for Fused Deposition Modelling}

Starting materials for FDM printing are made of thermoplastic materials and presented in the form of filaments produced mainly by hot melt extrusion of polymers. The first commercially available filaments produced for FDM printers were plastics such as PLA, ABS, high impact polystyrene (HIPS) and polyethylene terephthalate glycol-modified (PET-G) (41). These plastics produced in the dimension range of $1.75 \mathrm{~mm}$ and $2.85-3 \mathrm{~mm}$ to fit available printer heads, usually have high melting temperatures, and good mechanical properties. This ensures that they can be fed easily into the printer heads and withstand the heat and forces exerted by the extruder/printer gears. While there are many commercially available highquality filaments suitable for FDM printing, filaments are made from polymers unsuitable for pharmaceutical applications. Despite the abundance of pharmaceutical grade polymers, they often possess poor thermal and mechanical properties rendering them unsuitable for extruding and printing (65). There is therefore currently a growing interest and search for ways to improve the properties of available polymers and filaments to make them more printable or pharmaceutically suitable.

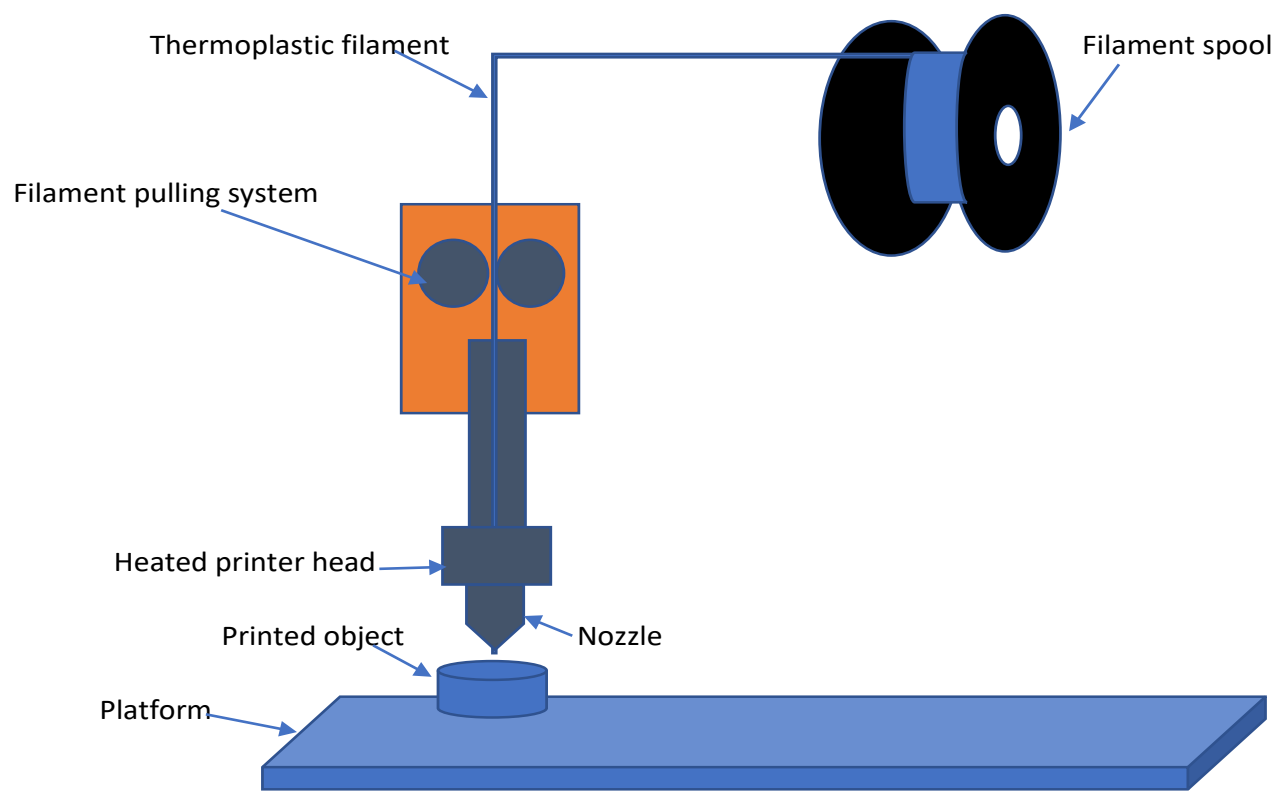

Figure 6: Schematic diagram fused deposition modelling showing the different parts of FDM printer; filament spool, heated printer nozzle and printing platform.

Some FDM oral dosage forms were printed using materials such as PLA, PVA and PCL (66), (67) (68) (69). PLA is a biodegradable polymer of great interest due to the many advantages that have been associated 
with its properties. PLA is a naturally occurring organic polymer produced from a non-toxic renewable source. PLA has grown in popularity since being deemed safe (GRAS) (70) by the FDA. It is also eco-friendly, biodegradable, recyclable and compostable, however its most attractive quality for application in the field of biomedical science is its biocompatibility (70). Although strength is limiting its applications, and properties for $3 \mathrm{D}$ printing making it one of the most commonly used polymers for fabrication of FDM filaments. PLA tensile strength is similar to ABS and used to print accurate parts. Due to its low printing temperature, it cools down quickly to prevent collapse, making the printing of sharp corners possible, and maintains the integrity of the printed shapes, but remains subject to thermal degradation at higher temperatures. A major drawback in the use of PLA for 3D printing of drug formulations is its hydrophobicity and slow degradation rate. PLA is relatively hydrophobic having a static water contact angle of about $80^{\circ} \mathrm{C}$, which is an undesirable property not only for biomedical applications where it elicits inflammatory responses in hosts but also in pharmaceutical drug formulation where dissolution and disintegration promotes drug release. (71) (72) (73)

PVA is another non-toxic, biocompatible and biodegradable polymer that is applied extensively in biomedical science. It is a hydrophilic synthetic polymer produced by the polymerisation of vinyl acetate via a free-radical mechanism usually in ethanol or methanol. The physical and chemical properties of PVA depend on the grade and molecular weight, determined by the percentage hydrolysis (74). PVA not only has a good tensile strength, hardness and flexibility but also possesses gas and aroma barrier characteristics (75). It is soluble in water and some water-miscible solvents such as formamide, dimethyl formamide (DMF) and dimethyl sulphate (DMSO) however, it is insoluble in other organic solvents, and only sparingly soluble in ethanol. In additive manufacturing by FDM, PVA is one of the thermoplastics of choice due to the relatively low melting point, which produces a melt viscosity that is high enough to build and low enough to extrude. PVA is commonly used to print support materials for complex designs and tubes, where removal of support material may prove difficult or impossible as solubility in water allows them to be easily dissolved by placing in water overnight. An important limitation to the use of PVA filaments/granules in the printing of materials is the hygroscopic nature of the polymer (76).

One of the drawbacks of FDM printing is the need for thermoplastic polymers and most pharmaceutical grade polymers are not thermoplastics. Recent studies explored the feasibility of producing FDM printable filaments using pharmaceutical grade polymers. Usually, this requires mixing polymers of pharmaceutical grade with excipients to produce processible filaments. Twin-screw extruders are preferred for the preparation of these filaments, as they allow homogenous distribution of drugs and excipients. To 
formulate theophylline loaded caplets, Pietrzak et al (77) used a mixture of drug, the plasticizers, triacetin, TEC, and the polymers; Eudragit RS, Eudragit RL and HPC SSL in different proportions and combinations. Melocchi et al (78) considered the use of insoluble, promptly soluble, enteric soluble and swellable/erodible polymers of HPC, HPMC, Eudragit and PVA (granules) for the fabrication of capsule shells and coating for immediate and modified release (Figure 7). The processability of filaments extruded were modulated using different types and amounts of plasticizers and relied on a trial and error approach to produce suitable formulations (60). Other than plasticizers, excipients in the form of pharmaceutical grade polymers have been tested and used to adjust polymer properties and produce printable filaments. Alhijjaj et al (63) formed polymer blends using polyethylene glycol and polyethylene oxide to improve printability and mechanical flexibility of Eudragit EPO and Soluplus. (79). On the other hand, Kollidon CLF used as a superdisintegrant by Zhang et al (80) improve dissolution and mechanical properties of some 3D printed tablets of paracetamol. Other polymers studied include poloxamer and PVP.
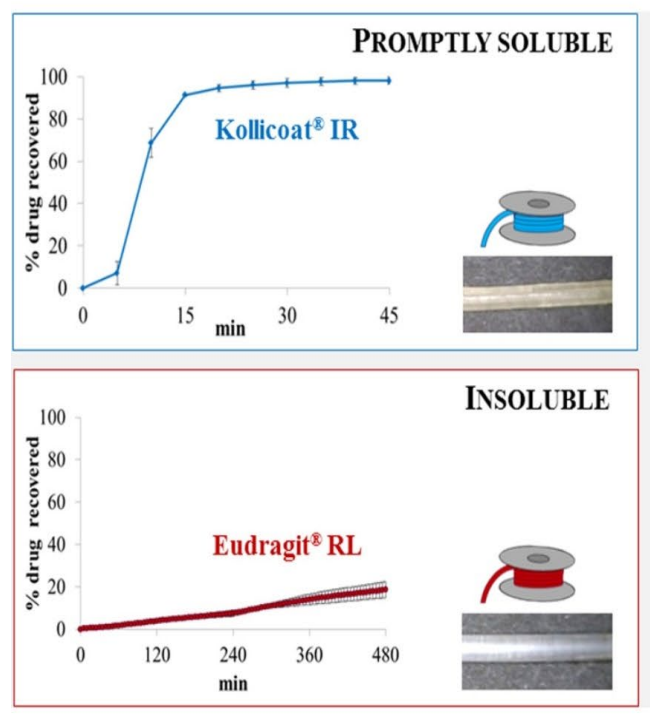

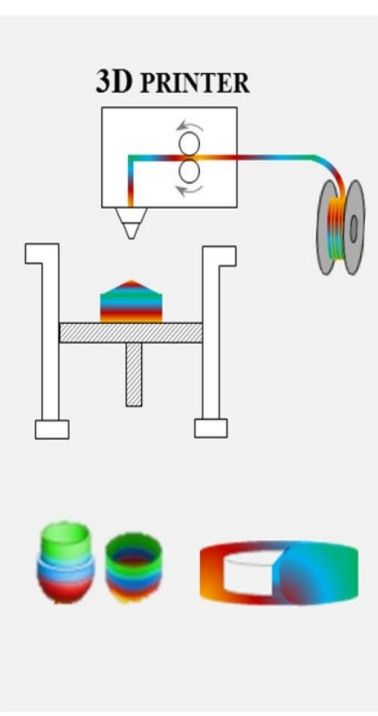

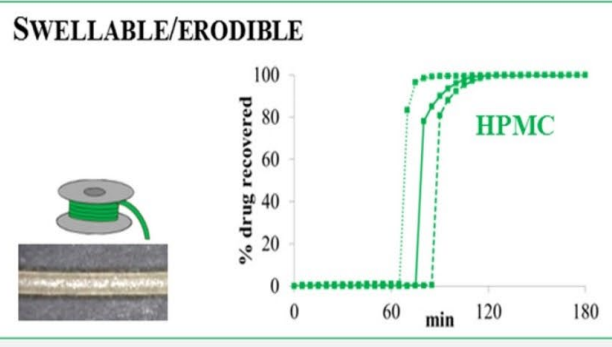

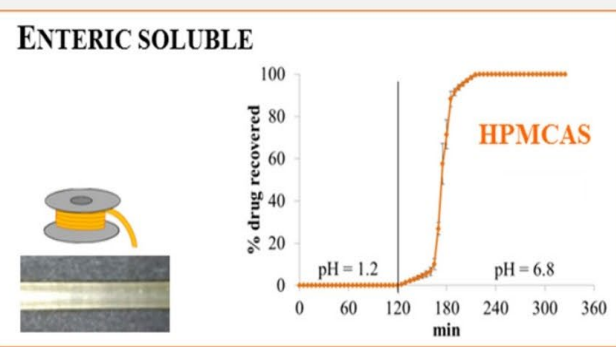

Figure 7: The use of extruder in the preparation of drug loaded filament showing different release profiles (56) 


\subsection{Incorporating APIs into Polymer Filaments for 3D Printing}

\subsubsection{Solvent Immersion}

Filaments from pharmaceutical grade polymers incorporated with active pharmaceutical ingredients (API) are not commercially available and therefore have to be prepared (81). Commercially available filaments such as PLA, PVA, and PCL have suitable mechanical properties for printing, however the successful loading of these filaments with APIs remains a challenge. The first filaments used for FDM printing of oral dosage forms were loaded with APIs by soaking commercial filaments in volatile solvent solutions (82) (27) (64) . Goyanes et al (64) produced amino-salicylic acid loaded filament by immersing commercial PVA filament in drug-saturated ethanol. This allowed the drug to passively diffuse into the filament and stay trapped on drying. Although this method was cheap, simple and required no heating, the percentage drug content reported for this method was rather low recording $0.004 \%$ for $4-A S A$ and $0.001 \%$ for the less soluble 5-ASA.

\subsubsection{Hot Melt Extrusion (HME)}

Recently hot melt extrusion (HME) was the main way of producing API loaded filaments. One HME based method of drug incorporation involves pelletizing and grinding of commercially available filaments mixed with active ingredient(s) prior to a hot melt re-extrusion. The grinding process is important as it ensures that the API (powder) and polymer have similar particle sizes. Mixing pellets with drug powder would lead to poor encapsulation and subsequently poor drug loading (66). To print budesonide tablets, PVA filaments were cut into small cylindrical pellets that were roughly $2 \mathrm{~mm}$ in length and ground to fine powder, which was passed through a sieve of mesh size $1000 \mu \mathrm{m}$. Budesonide was mixed with the powdered polymer and the mixture was extruded using a single screw extruder (83). This method produced filaments with higher percentage of drug content and good mechanical strength suitable for printing. HME also has the added advantage of being able to improve the bioavailability of poorly soluble drugs.

As mentioned previously, the FDM method does not have to rely solely on commercial grade polymer filaments but can also use HME to generate custom-made filaments. Most available extruders are in the form of single screw extruders and these do not provide enough mixing for homogenised content of customized filaments. While number of researches using FDM printed oral dosage forms with commercially available filaments has dwindled since 2014, there is an increasing number of researches exploring the use of all kinds of pharmaceutical grade polymers for the extrusion of filaments. Using an extruder, any kind of polymer is converted to a filament with desired properties. Polymers explored for this method include cellulose-based polymers (hydroxypropyl cellulose, HPC SSL) (80) and methacrylic 
polymers (Eudragit RL, RS and E). Customisation of filaments from these powdered polymers eliminates the need for the pelletizing and shredding required when using commercial filaments as well as the need for solvent. Kempin et al (63) mixed powder blends of polymers (e.g. PEG and PVP) with pantoprazole and other liquid excipients (TEC plasticizer) and ensured even distribution of drug in polymer by grinding them separately before mixing.

\subsection{Printing and extrusion parameters for FDM filaments}

Using too high extrusion temperature can lead to degradation of thermolabile drugs while using too low temperature can cause nozzle blockage (77). Printing temperature should be high enough to convert the polymer filament into a semi-solid form in the printer nozzle but must cool and solidify fast enough at the temperature of the printer platform to support the deposition of the next layer of polymer. This usually occurs at temperatures between $220^{\circ} \mathrm{C}$ and $260^{\circ} \mathrm{C}$ for polymers such as PLA and ABS, which have been optimised but not for methacrylic polymers which degrade at a relatively lower temperature of $166^{\circ} \mathrm{C}$.

Pietrzak et al adapted FDM printing for methacrylic polymers by adding a component of high melting point of $273^{\circ} \mathrm{C}$, theophylline, to the polymer of choice Eudragit RL (printing temp $170^{\circ} \mathrm{C}$ ) and printed caplets at temperature below that recommended by printer manufacturer and previous reports (77). The FDM printing temperature used was also several degrees higher than that used for extrusion of filaments since the polymer blend required longer heating time in the HME during filament extrusion than the nozzle heating time of the 3D printer. This method would most likely be unsuitable for printing of thermolabile drugs. Pantoprazole (MP: $143^{\circ} \mathrm{C}$ ) a more thermo-sensitive, suitable polymer candidates was selected and optimized for printing by Kempin et al (63). The printing temperatures was $100^{\circ} \mathrm{C}$ and included water soluble polymers such as PEG and PVP, while excluding polymers such as PVA and Kollicoat after they were shown to require extrusion temperatures above $100^{\circ} \mathrm{C}$ during testing.

For the printing of drug loaded PVA tablets by Goyanes et al (64), the recommended printing temperature of commercial PVA polymer was $190-220^{\circ} \mathrm{C}$ and the melting temperatures of the components of choice were $180^{\circ}, 130^{\circ} \mathrm{C}$ and $268^{\circ} \mathrm{C}$ for PVA, 4-ASA and 5-ASA respectively. The drug-PVA filaments were printed at $210^{\circ} \mathrm{C}$ and resulted in drug degradation and reduction in drug content for 4-ASA but not for 5-ASA. For a method that required no HME and restricted drug heating to the time spent in the printer nozzle, the extensive degradation of the 4-ASA showed the importance of even a brief heating on thermolabile drugs. TGA and DSC analysis have proven to be very useful in predicting degradation temperatures of drugpolymer mixtures (63). Table 3 compares the melt temperature of polymers and drug to tablet processing temperature. 
Table3: - Comparison of FDM polymers and drug melt temperature to tablet processing temperature

\begin{tabular}{|c|c|c|c|c|c|c|}
\hline Polymer & $\begin{array}{l}\text { Polymer } \\
\text { Melt onset } \\
\text { temp }\left({ }^{\circ} \mathrm{C}\right)\end{array}$ & Drug & $\begin{array}{l}\text { Drug Melt } \\
\text { temp }\left({ }^{\circ} \mathrm{C}\right)\end{array}$ & $\begin{array}{l}\text { Solvent } \\
\text { drying } \\
\text { temp }\left({ }^{\circ} \mathrm{C}\right)\end{array}$ & $\begin{array}{l}\text { HME temp } \\
\left({ }^{\circ} \mathrm{C}\right)\end{array}$ & $\begin{array}{l}\text { Print } \\
\text { temp }\left({ }^{\circ} \mathrm{C}\right)\end{array}$ \\
\hline PVA (66) & 175 & Paracetamol & 168 & ------ & 180 & 180 \\
\hline PVA (64) & 180 & 5 ASA & 278 & 60 & $\begin{array}{ll}--- \\
\end{array}$ & 210 \\
\hline $\begin{array}{l}\text { PVAFormatting... please } \\
\text { wait (82) }\end{array}$ & 180 & $\begin{array}{l}\text { Fluorescein } \\
\text { sodium }\end{array}$ & 320 & 60 & ---- & 220 \\
\hline PVA (27) & $160-170$ & $\begin{array}{l}\text { Prednisolon } \\
\text { e }\end{array}$ & 203 & 40 & & 250 \\
\hline PVP (84) & 169 & $\begin{array}{l}\text { Theophyllin } \\
\text { e }\end{array}$ & 270 & ---- & 90 & 110 \\
\hline PVP (84) Formatting... & 169 & $\begin{array}{l}\text { Dipyridamol } \\
\text { e }\end{array}$ & 165 & ----- & 90 & 110 \\
\hline $\begin{array}{l}\text { Eudragit }{ }^{\circledR} \text { RL PO } \\
\text { PLA (48) }\end{array}$ & $\begin{array}{l}145 \\
150\end{array}$ & Metformin & 235 & ----- & $140-157$ & 170 \\
\hline $\begin{array}{l}\text { PVA Mowiol } 4-88^{\circledR} \\
\text { Formatting... please wait } \\
\text { Mannitol (69) }\end{array}$ & $\begin{array}{l}195 \\
170\end{array}$ & glimepiride & 217 & ----- & 190 & 205 \\
\hline PVA (85) & 175 & $\begin{array}{l}\text { Paracetamol } \\
\text { caffeine }\end{array}$ & $\begin{array}{l}169 \\
238\end{array}$ & $\begin{array}{l}----- \\
\end{array}$ & 180 & 200 \\
\hline PVA (83) & 175 & Budesonide & 250 & ------ & 170 & 190 \\
\hline
\end{tabular}


Another important challenge in the preparation of loaded filament by HME is the fabrication of filaments with adequate mechanical properties. A filament fit for the 3D printer cannot be too brittle, as that would cause breakage by the feeding gear (81). On the other hand, a too soft filament is compressed and pushed aside by the gear. Commercial printers are designed to print plastics such a PLA and ABS with mechanical properties that can be considered ideal in terms of stiffness, toughness and viscosity. Studies involving printing of hot melt extruded filament from polymer blends usually applied a trial and error method to generate printable tablets. Sadia et al (86) assessed compatibility of extruded filaments with nozzle printer heads based on the flow of melted polymer from the nozzle. Filaments broke within the printer gears due to being brittle, and filaments bent between the gear and nozzle were too flexible. PLA was used as a reference to compare commercial filaments to extruded filaments made from different combinations of polymers such as HPMC, EC, HPC, Eudragit and Soluplus. To test the filament characteristics of the polymer blends, an analyser and a 3-point bend probe set were used to measure the stiffness and brittleness of the extruded filaments. The polymer filaments produced were screened and optimised based on these characteristics. Another method of filament analysis known as the Dynamic micro-indentation test technique was demonstrated by Gioumouxouzis et al (69) and involved the use of a dynamic ultra-micro hardness tester. The tester was fitted with a triangular pyramid indentation tip to apply controlled load onto a filament which had been held in place on a surface. The penetration depth of this indentation was recorded continuously as a function of load. Nasereddin et al recently developed a screening method of determining the filament feedability using a texture analyser (87).

\subsection{Characteristics of FDM printlets}

While drug dissolution is prompted by the swelling and disintegration in conventional compressed tablets, FDM printed tablet dissolve and release drug components primarily by erosion and diffusion. The dissolution speed of FDM printed tablets are known to be very low compared to compression-based tablets. This is as a result of the nature of polymers used and the compactness of the melted filaments. FDM has therefore extensively been applied in many studies to produce modified (extended and sustained) release dosage forms (8) (88) Formatting... please wait. Eudragit-based tablet extended drug release over 16-hour period and left an empty insoluble matrix in the dissolution medium, see Figure 8 (77). Attempts have been made to improve release rate of FDM tablets by selecting polymers, which have immediate release properties, formulating polymer blends to include polymers that behave as disintegrators, incorporating hydrophilic non-melt fillers into the polymer blends and reducing the infill percentage during tablet printing. 

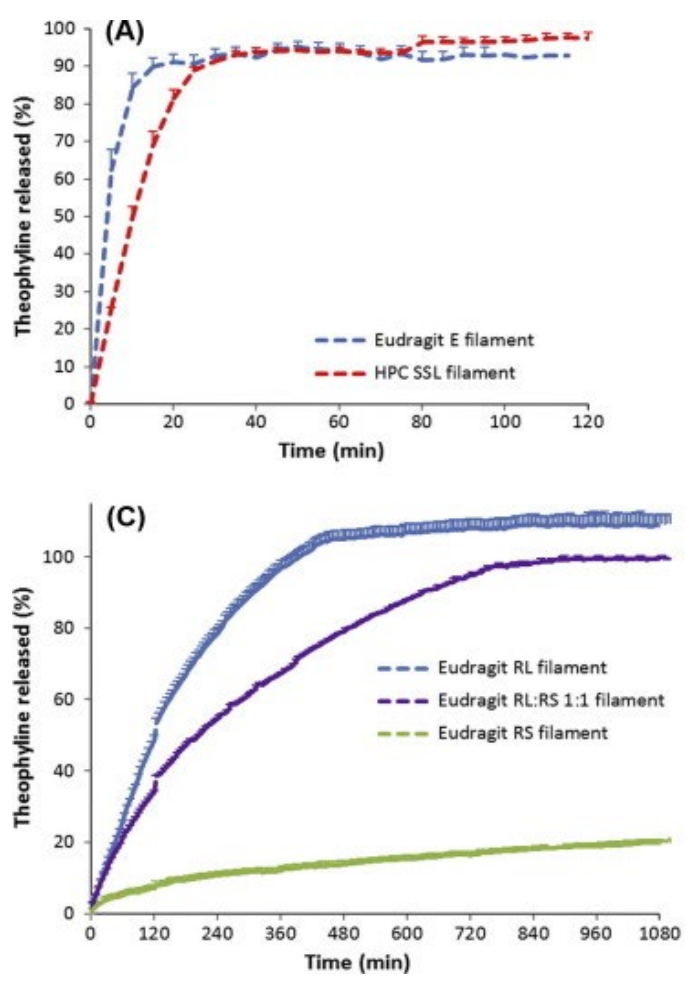

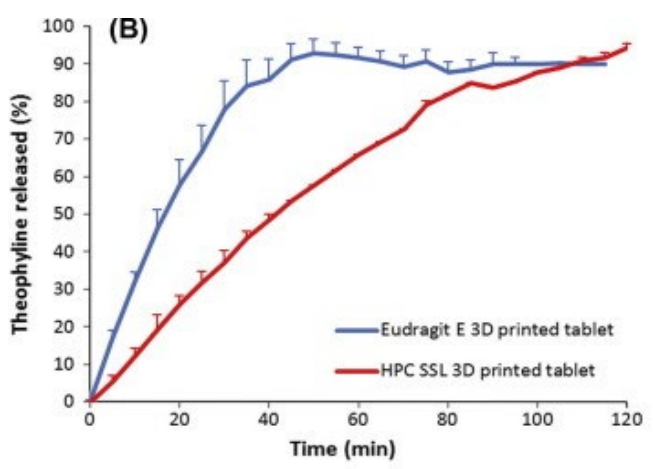

(D)

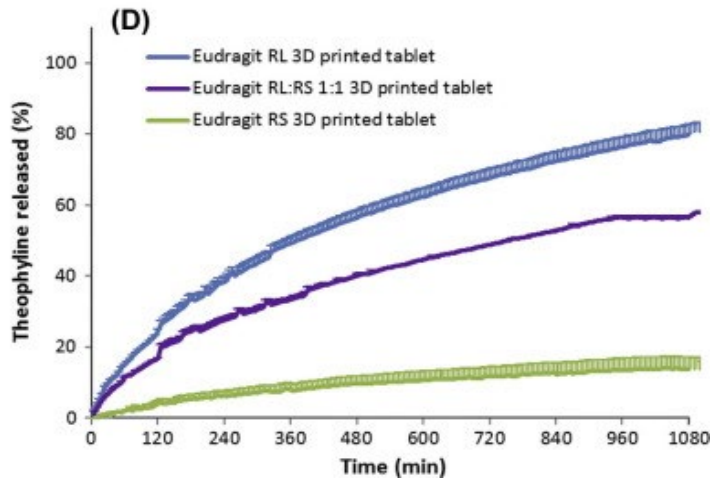

Figure 8: In vitro drug release of theophylline compared to filament using ( $\mathrm{A}$ and $\mathrm{B}$ ) immediate release polymers such as HPC SSL and Eudragit E, and ( $C$ and D) extended release polymers: Eudragit RS and Eudragit RL, their 1:1 mix (77) (78)

Although FDM printing has focused mainly on extended release tablets until recently, however more than $70 \%$ of orally administered dosage forms are intended for immediate release (89). It would therefore be of great importance to adapt FDM printing to pharmaceutical materials and drug products that release active ingredients immediately. One of the earliest attempts was presented in a study by Pietrzak et al (77) which explored the use of FDM and HME 3D printing methods to control the release of theophylline tablets from a range of polymers including HPC SSL and Eudragit E which are polymers used for immediate drug release. The result of the study showed that although the unprinted polymer filaments of Eudragit $E$ and HPC SSL were able to release majority of the drug within 25 minutes, the printed tablets extended drug release over a longer period. The poor dissolution of printed tablets was attributed to the loss of surface area of the filaments after printing. However, in a subsequent study by Sadia et al (86) caplets formulated by FDM printing of drug-loaded Eudragit EPO showed immediate release of more than $85 \%$ of the APIs (theophylline, captopril, prednisolone and 5-ASA) within 30 minutes. Similar results were obtained by Okwuosa et al (84) using FDM printing to generate immediate release tablets of dipyridamole 
and theophylline from PVP filaments. These two later studies unlike the former incorporated non-melting fillers into the drug-polymer-plasticizer filament matrix.

Kempin et al (63) used five different pharmaceutical grade water-soluble polymers of PVP K12, PEG 6000, Kollidon ${ }^{\circledR}$ VA64, PEG 20,000 and poloxamer 407 to produce immediate release tablets of thermosensitive pantoprazole. The PEG 6000 and PVP K12 based tablets recorded the shortest release time at 29 mins and 10 mins respectively. By cutting down the infill percentage to 50\% in the PVP K12 tablet, dissolution time was reduced to 3 minutes. The use of disintegrants to achieve immediate drug release from compressed tablets is well-established in conventional tablets production. However, the addition of disintegrants to FDM printed tablets seemed to show little effect on drug release rate. Since most disintegrants credit their mechanism of action to water imbibition and swelling, FDM printed tablets appear to prevent this process. Sadia et al (90) attributed this to the possible coating of disintegrant particles by melted polymers during printing.
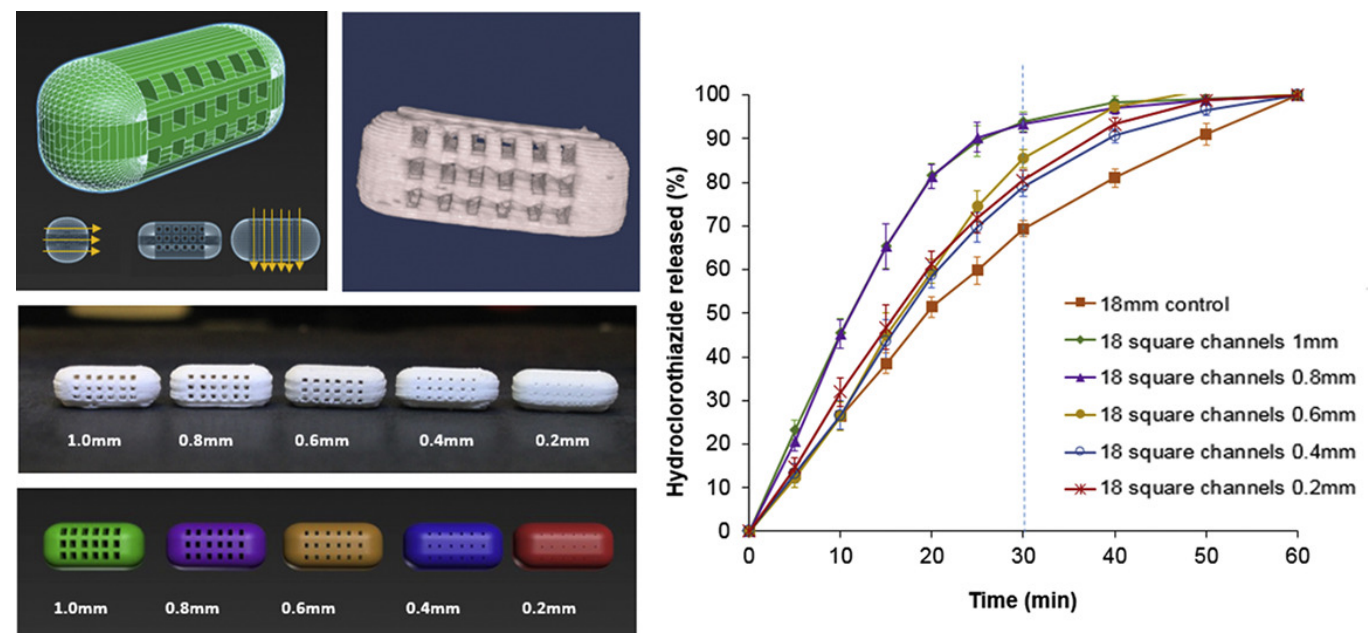

Figure 9: Schematic illustration of caplets with square-sectioned channels (top-left), photographs (centre-left) and rendered images (bottom-left) of caplet designs with decreasing channel sizes and the corresponding drug release profile (right) (90)

\section{Powder-bed Inkjet Printing}

Inkjet printing generally refers to deposition of materials dispersed in a solvent or system of solvents by ejecting them onto a substrate through a nozzle (91). Of the three mechanisms used commercially in droplet generation (92), the DoD has been involved in most of the published work about additive manufacturing. While EIJ printing has only recently become commercially available, DoD is well reviewed and known to be more precise and less wasteful than $\mathrm{CIJ}$ printing. This is because droplets generated by 
DoD have sizes in the $1 \mathrm{pl}$ to $1 \mathrm{nl}$ range, droplets are mechanically placed in predetermined positions and are not steered while in motion. There are two commonly used systems of droplet formation in DoD printing; the thermal and piezoelectric printing methods. Piezoelectric applies voltage to a piezoelectric material deforming it to cause an ejection of liquid droplet through the nozzle. When it is compared to thermal actuation, piezoelectric printing offers more control about droplet formation and does not work by generating heat. Therefore, it is more suitable for pharmaceutical applications. In thermal inkjet system droplets, on the other hand, are ejected when localised heating of liquid causes bubbles to form and expand (93). This system of printing has the added risk of heat degradation of ingredients in addition to the limitations caused by solvent restrictions and poor mechanical strength. Inkjet printing has been also applied in genomics, drug delivery, material screening, biomaterials and life sciences due to the high level of precision, automation and reproducibility of the technology (94), (95), (96) (97) Formatting... please wait. In drug delivery, inkjet printing was used to load micro-needles (98), improve dissolution properties of poorly soluble drugs and control release of dosage forms by ensuring content uniformity (93).

Inkjet printing technology is used in the fabrication of 3D printed objects with high resolution. This is achieved through multiple and successive deposition of jetted layers of materials onto a flat platform. Studies involving layer by layer inkjet deposition of curable resins and thermoplastics have been reported (99) (100) However there are limited pharmaceutically approved materials that can be used for these processes. Usually, for the printing of pharmaceutical dosage forms, the powder bed method of 3D printing is employed, as most approved polymers are in form of powder materials.

In powder bed or drop on solid method of inkjet 3D printing, a binder material is used to join layers of powder, which are successively levelled on a powder bed, supported by a piston and contained in a cylinder (Figure 10). An inkjet droplet dispensing system, usually piezoelectric or thermal is used to apply the binder material on the area of the bed where the printed part is, to join each new layer to the forming part. The piston lowers the powder bed after each binder application to allow a new layer of powder to be spread on the bed surface. This process is repeated until the designed part is formed and then the unbound powder is removed. The printing machine is made up of two horizontal axes $X$ and $Y$ held over the vertical piston allowing control of the nozzle movement in three directions (101). Powders used for this method of printing include ceramics, metals and polymers. In a 1995 report, Wu et al (28) fabricated resorbable polymeric drug delivery devices that displayed controlled drug delivery by specifying the composition and position of binder materials as well as the microstructure of the delivery system. 


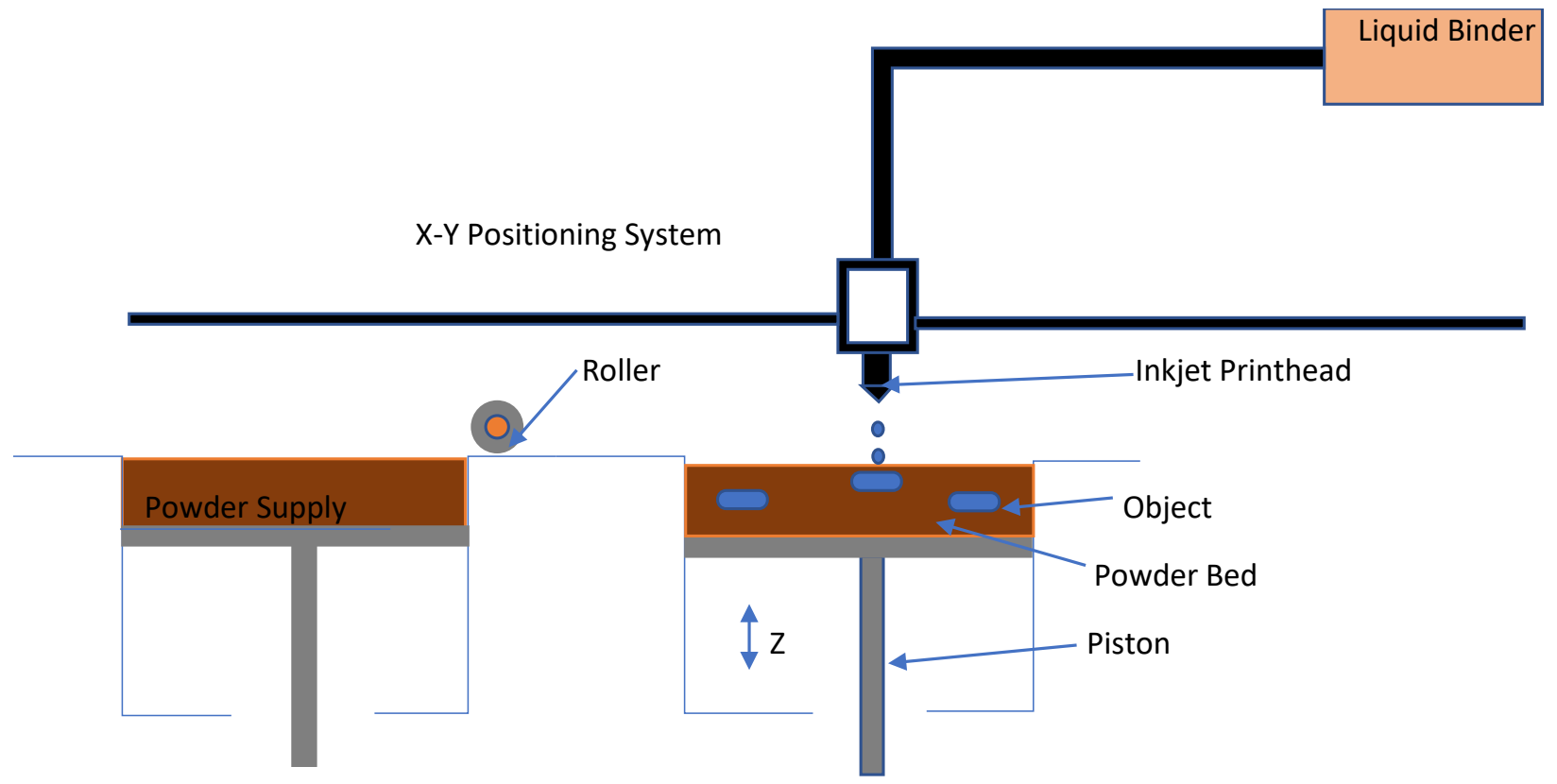

Figure 10: A Schematic diagram of Powder bed-inkjet printing showing the main components of the printer including liquid binder, printhead, powder supply and powder bed.

Parameters such as layer thickness, spacing between printed lines and flow rate of liquid binder control the microstructure and subsequently the release profile of printed dosage forms (28). Katstra et al (102) investigated the feasibility of producing oral drug DDD using pharmaceutical grade ingredients. The study aimed to assess the effect of printing parameters on drug dosage, spatial positioning and drug release control. Chlorpheniramine tablets were made using powder bed formed with cellulose powder and spray dried lactose as well as binder solutions formed with Eudragit ${ }^{\circ}$ E-100, Eudragit RLPO or Kollidon PVP. Drug release from printed tablets was based on diffusion and erosion. The lag times and release rates of the different tablets were dependent on the polymer quantity printed onto the tablets. A fluorescein study confirmed the accuracy of droplets placement and demonstrated dosage uniformity of the tablets.

More complex oral dosage forms fabricated by Rowe et al (103), tested formulation flexibility by mixing different release mechanisms in one formulation. Immediate-extended release tablet were made of Eudragit ${ }^{\circ}$ E-100 and Eudragit RLPO and showed erosion based chlorpheniramine release from the soluble E100 polymer section within 30 minutes. The insoluble polymer section released the drug over a 6-hour period by diffusion (Figure 11). A batch of 3-layered breakaway tablets formulated and used a mixture of Avicel PH301, spray dried lactose and Eudgragit ${ }^{\circ}$ L100 to form the powder bed. A fast dissolving middle layer printed with a solution of Kollidon K-25 in water, separated two drug-polymer layers. The drugpolymer layers were printed with a binder solution of Eudragit ${ }^{\circ}$ RLPO in acetone for the placebo layer, 
which surrounded the drug layer printed with diclofenac, Kollidon K-25 in methanol. These tablets when placed in a dissolution medium, split into two after the fast dissolving middle layer completely eroded. Another batch of tablets, the dual pulse release tablets, were formulated using the $\mathrm{pH}$ dependent release polymer, Eudgragit ${ }^{\circ}$ L-100, as binder and showed two release pulses 4 hours apart. To prepare fast disintegrating tablets, Yu et al (104) prepared powder layers from a blend of paracetamol, lactose, PVP K30, mannitol, and colloidal silicon dioxide. The binder solution was prepared with PVP K30 mixed ethanol in water and the colour marked with methylene blue. The tablet characteristics ensured fast disintegration having a hardness of $54.5 \mathrm{~N} / \mathrm{cm} 2$, wetting time of 51.7 seconds and disintegration time of 21.8 seconds. The friability value was relatively high at $0.92 \%$.

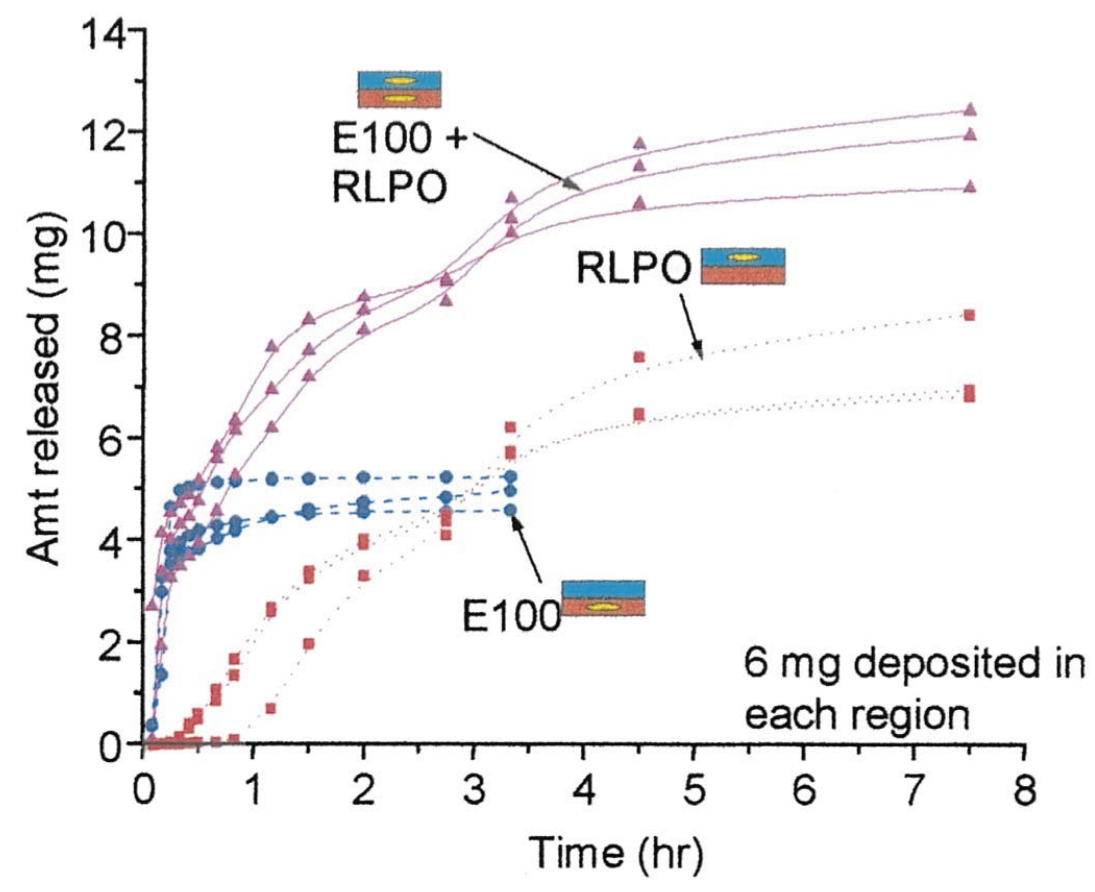

Figure 11: dissolution profiles of immediate -extended release tablets, breakaway tablets and dual pulse release tablets $(103)$

A study by Clark et al (105) investigated the viability of combining inkjet printing with stereolithography in the fabrication of oral dosage forms. UV-curing was used previously in inkjet printing industry to provide instant polymerization of materials on demand (105) however, no previous studies used UV curable inkjet formulation in the fabrication of dosage forms for oral use. The ink used was formed from a mix of Irgacure 2959 photoinitator, ropinirole $\mathrm{HCl}$ active ingredient and poly (ethylene glycol) diacrylate (PEGDA) as the 
photopolymerizable resin. The piezoelectric drop on demand method was used to deposit the ink onto a poly(ethylene terephthalate) (PET) film substrate, while a UV laser source attached to the nozzle printer head followed the path of the printer head, curing materials as they are deposited. The drug loaded tablets showed a high degree of crosslinking and displayed a Fickian drug release profile.

\section{Strategies and approaches for Personalisation of printlets}

Many applications of 3D printing in medicines and medical devices were geared towards production of personalised dosage forms, doses, implants and other products which improve patient compliance and adherence (38). One of the many forms of personalisation is the design of multi-layered tablets with one or more API in each layer. This would be ideal for treatment of patients with co-morbid illnesses that have resulted in polypharmacy. Fixed dose combination treatment described in other studies are marketed as Polycap for cardiovascular diseases with associated co-morbidities. The major limitation to this development, however, is the lack of flexibility as the doses are fixed and cannot easily be changed by the conventional compaction method. Multi-layered dosage forms (illustrated in 5a) can be fabricated using a multi-material 3D printer and in cases where the printer technology is not adapted for multi-material printing, modifications to the available printer can be made. A six layered polypill containing naproxen, paracetamol, caffeine, aspirin, chloramphenicol and prednisolone was fabricated by Robles-Martinez et al (60) using the SLA method of 3D printing and the physical characteristics of the polypills as well as the influence of geometry and addition of excipients on the rate of drug release was evaluated. Since the hardware and software that allow for multi-resin printing are commercially unavailable, certain adjustments accomplish the redesign of software and periodic manual changing/replacement of resin. The multi-layered printlets successfully fabricated with individual drug components residing majorly in their separate compartments evidence of diffusion in the layers containing aspirin, naproxen and paracetamol. To prevent diffusion of drug components between layers of a polypill, a segment is printed between the different layers of the dosage form using an appropriate barrier polymer. A five-component polypill designed based on the commercially available "Polycap" used a segmented tablet strategy to ensure the separation of the APIs. Barriers between the sustained release layer and the immediate release layer was created using a hydrophobic membrane made of cellulose acetate (106). HPMC was used to sustain the release of pravastatin, atenolol and ramipril while the immediate release of aspirin and hydrochlorothiazide was achieved with the help of sodium starch glycolate disintegrant. Preparation of release matrix with different concentrations of the same polymer is another way by which drug release 
can be controlled for printed tablets. Printing of multi layered dosage forms could provide benefits such as reduced cost of treatment and increase patient compliance (106).

Additionally, independent drug release between the layers of these printlets can be obtained using different means. One way of achieving different release rate between layers is by using polymers with different release properties. Bi-layered tablets prepared by FDM printing were formulated to incorporate different dose regimen of metformin and glimepiride. The Eudragit layer of the tablet was able to sustain release of metformin for 480 minutes, while the PVA layer released the glimepiride within 75 minutes (48). Different concentration of the same polymers obtained different release profiles. To prepare bilayered guaifenesin tablets (10), guaifenesin paste was made of HPMC of different viscosities for the sustained and immediate release layers. The printing method applied for this study was the syringe assisted extrusion-based 3D printing using a desktop printer with two printer heads and syringe tools.

While the above studies relied on the nature of the polymers and excipient manipulation to determine release behaviour of printed dosage forms especially in term of duration, a more active approach towards controlled release can be achieved by designing and fabricating complex geometries, macrostructures and microstructures. Goyanes et al (82) described the effect of infill percentage of FDM printed PVA tablets on weight, structure and drug release. Tablets with lower infill were hollower and possessed more cavities. These tablets which released the drug primarily by erosion, showed an infill-dependent drug release with lower infill tablets releasing drug faster than tablets of higher infill percentage (107). Alternatively, channels of defined dimensions can be purposefully created in the FDM printed tablets (see figure 9). Sadia et al (90) was able to design and fabricate FDM caplets incorporated with channels of different dimensions (Figure 9). The study showed that with increase in the width of channel, there was an increase in the rate of drug release. Fabrication of printlets with openings in the form of gyroid lattices was demonstrated and analysed. A review by Mellocchi et al (108) discussed the use of FDM printing for the fabrication of hollow systems grouped these devises into systems with a single compartment and systems with multiple compartments which could be partly empty or filled. Floating hollow systems designed to be empty are usually fabricated by reducing infill percentage and would sometimes have the API(s) contained in the shells while maintaining the low density and buoyancy required for gastroretention and extended drug release (88). In a partly filled system fabricated by Huanbutta et al (109), which comprised of a cap and a body, API was housed within the core of the device body in the form of an immediate release tablet with an orifice at the bottom to control drug release and floating was achieved by creating air volume within the top. 
SLS printing was used to produce cylindrical, gyroid lattices and bilayer structures and the porosity of the printlets was determined. It was observed that the openings in the gyroid lattices enhanced their porosity giving them a higher porosity value than the cylindrical printlets. The duration of dissolution from the gyroid lattice printlets was less than the other fabricated printlets. This was attributed to the increased surface area and porosity (7). Yu et al (104) used drop on demand inkjet-powder bed 3D printing technique to produce fast disintegrating tablets by controlling parameters such as droplet spacing and line to line spacing. The top six layers and the bottom six layers of the cylindrical shaped tablets were fully printed by depositing the binder liquid to fully cover the circular cross-sections that form these layers (Figure 12). The twelve middle layers were only partially printed with the binder solution deposited to cover only the peripheral rings of these layers thus leaving a lot of free powders in the centre of the printlets.
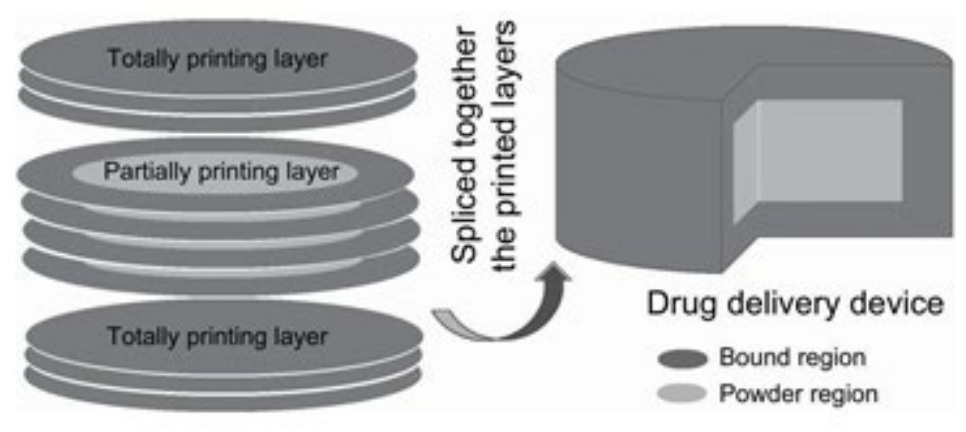

Figure 12: - A schematic diagram of a fast disintegrating PB-inkjet 3D tablet fabricated by selective deposition of binder solution with fully printed top and lower layers and partially printed middle layers containing the drug in a powder form (103)

Manipulation of shapes of printlets controlled the drug release profile. Martinez et al (59) made use of SLA 3D printed tablets to study how geometric shapes influence their drug release profiles. Printlets of different shapes including pyramidal, cylindrical, spherical, cubical and torusal were fabricated using PEGDA. The study demonstrated that at a constant surface area to volume (SA/V) ratio, the different shapes of printlets displayed the same release profile. Torus shaped tablets with increasing SA/V ratio were also printed and showed a corresponding increase in dissolution rate. SLA was found to be a suitable 3DP technology for manufacturing tablets of different shapes with dissolution properties that can be controlled by varying SA/V ratios, making the creation of personalized dosage forms possible. Similarly, a study by Goyanes et al (66) described the influence of geometric shapes on drug release in FDM printed 
tablets. At constant surface area, the order of drug release for different shapes of tablets from the fastest to the slowest was pyramid $>$ torus $>$ cube $>$ sphere and cylinder.

\section{Benefits and Limitations of 3D Printing Solid Dosage Forms}

\subsection{Benefits}

\subsubsection{On-Demand Manufacturing}

3D printing techniques can allow easy fabrication of quality product within a few minutes. On demand manufacturing by 3D printing can be especially useful in situations where time and materials are limited, in drug development for quicker optimization as well as in the fabrication of drug products with poor stability (38). This is more possible by the availability of desktop printers. There are already reports on inkjet printing of low stability drugs and the use of 3D printing for the production of low stability drugs has been proposed.

\subsubsection{Dosage Flexibility}

Customisation of medicines to the needs, preference and characteristics of individual patients is an old idea that has flourished with the progress in diagnostics (110). Dosage tailoring would be especially useful in paediatrics where there is a wide weight to age variation. The variability in treatment between individuals stemming from the differences in their backgrounds, metabolisms and needs is a widespread problem that is managed by grouping patient population based on certain biomarkers. Better management through 3D printing is achieved by personalisation. Personalisation and dose tailoring would also be helpful in reducing non-compliance resulting from the prescription of multiple medications. Medication non-adherence resulting from polypharmacy is reported to reach $35 \%$ rate in patients taking more than four medications (111). Research has shown a prevalence of polypharmacy among the elderly population (112) which has been strongly linked to negative consequences including adverse drug reactions, interactions and medication non-adherence (113) (114). Poor adherence in the geriatric population has been associated with complex dosing regimen with community-dwelling elderly patients rating between 43 and 100\% in non-adherence (115) (116). Personalisation when applied to dosage forms via 3D printing allows dose and combination modification to meet individual patient need. Doses can be adjusted based on each patients weight and age while also taking into account their pharmacogenetics and pharmacokinetics 


\subsubsection{Improved Quality Dosage Forms}

The use of computer-aided designs coupled with the desktop printers is expected to provide better control of the several variable parameters involved in 3D printing of tablets. Critical parameters such as scan speed, laser power and temperature are controlled by the printer system leading to high reproducibility. Furthermore, fewer processing steps are required for product manufacturing by 3D printing compared to conventional methods of formulation. In most conventional drug product formulation, steps such as granulation, milling, compression, coating and drying are essential and the increased number of steps involved in these procedures may lead to higher risk of batch failure (24) due to increased chances of errors.

\subsubsection{Design Flexibility}

While the traditional drug manufacturing methods usually rely on the shapes of relevant moulds to determine the shape of tablets, caplets and capsule shells, 3D printing allows innovative product designs. The distribution of active ingredients and excipients within the dosage form is controlled and the design manipulated to allow multiple active drugs to be strategically incorporated within predetermined sections or layers. The properties of a dosage form in terms of macrostructure, microstructure and composition can have great influence on drug release. For example, the design of a solid dosage form into highly a porous structure can reduce disintegration time, hence enhancing drug release. Colours, shapes and flavours are adjusted to suit the paediatric population and oral disintegration can be designed to meet the need of geriatric, paediatric and dysphagic patients.

\subsection{Limitations of 3D printing techniques}

The physical appearance of some 3D products may not be appealing to patients. Certain printing technologies produce printlets with rough or imperfect surfaces resulting from removal of support materials from FDM printlets or porous structure of SLS printlets. Products are not aesthetically pleasing to patients, may cause poor patient compliance. Further, some 3D printing techniques such as stereolithography require the use of materials which may have unknown health risks. Most approved polymer resins and photopolymerization initiators have some suspected carcinogenic risks. This places a restriction on the use of these methods in the formulation of oral dosage forms. Another important limitation is the need for the use of lasers and high-energy sources in methods such as stereolithography and SLS printing which may result in degradation of unstable drugs. Similarly, thermal degradation may also restrict the use of FDM printing to thermally stable drugs and excipients. FDM printing is limited by the need for thermoplastic polymers and extrusion of filaments. Printing of fast disintegrating tablets 
using the powder bed printing technique compromises the mechanical strength of printlets causing high friability and low hardness. Certain printing equipment are costly such as that used in stereolithography. Post printing processes like curing and drying are required in SLS, SLA and powder bed 3D printing, lengthening the print duration.

\section{Regulatory challenges and quality control}

Some of the most commonly debated issues on 3D printing of medicines and devices are questions about regulation and liability, if the product causes an adverse effect or fails. Is it the manufacturer of the printer, ink or the final product (the healthcare professional or the organization they represent)? (117) Another question posed is the level of regulation that 3D printed medicines should be held to. Should regulation be similar to those of manufactured or compounded medicines? (118)

Personalised medicines seem to share a lot more similarities with compounded medicines than manufactured dosage forms especially in terms of level of possible risks. Although risks associated with customized medicines made for individual patients may not be as hazardous as those of traditionally and mass-produced batch medicines made for patient groups, both types of medicines undergo high levels of examinations. Care should be taken however, to ensure that safety of use of medicines is balanced with ease of access to medicines as both needs are equally important. Sufficient regulations needs to be in place to make 3D printed medicines safe for patients, but not enough to discourage the manufacturers, frustrate their innovative efforts and subsequently hinder patients access to treatment.

How should 3D products be tested? With traditionally manufactured products, random samples from each product batch are selected for quality control tests with inspections and measurements after manufacturing. Although similar methods can be applied to mass-produced 3D printed medicines, the same cannot be said for personalised or customized drugs made for individual patients. Since the production of personalized products would be at a smaller scale, certain non-destructive tests could be carried out on all of the products. Studies on some non-destructive analytical techniques may be useful for personalized medicines. Trenfield et al (119) evaluated the use of process analytical technology (PAT) on paracetamol loaded 3D printed tablets. Near infrared spectroscopy was used to develop a calibration model that could predict drug concentration across a stated range with impressive linearity and accuracy. The study also used Raman confocal microscopy to demonstrate even distribution of the drug within the tablet. Similarly, non-destructive quality control was tested on inkjet- printed theophylline formulation using hyperspectral imaging technique by Vakili et al (120). When non-destructive techniques of testing are not available or applicable, more products than needed could be printed, and the destructive quality 
control tests can be performed on the excess. Otherwise, regulatory measures need to place a lot more emphasis on other quality assurance and management steps that lead up to product formation by devising approaches to ensure quality throughout the production process.

\section{Conclusion}

The need for a personalized dosage forms coupled with the technological advancement in additive manufacturing technology has led to a growing interest in using 3D printing in manufacturing of dosage forms. Incorporation of 3D printing into drug products manufacturing is expected to bring the muchneeded improvement to the conventional methods of production, which are known to be outdated in terms of flexibility and efficiency.

3D printing technologies such as fused deposition modelling, semi-solid extrusion, selective laser sintering, inkjet printing and stereolithography have been used in printing oral solid dosage forms. Each $3 \mathrm{~d}$ printing technique has offered a number of advantages but yet has limitations still to be overcome. For instance FDM was an easy and cheap option for printing oral solid formulations, yet affects the stability of thermos-labile drugs and only limited polymers are available for filament manufacturing. Many current research studies aim at matching desired drug characteristics to suitable type of 3D printing or devising ways around known limitations. With advancement in 3D printing of pharmaceuticals, there are expected changes in the regulatory aspects as most of the current regulations are centred on the over 200-year-old traditional medicine manufacturing. It is evident that with all the new and potential developments in medications 3D printing will come several regulatory adjustments to accommodate these changes.

\section{REFERENCES}

(1) Essa K, Hassanin H, Attallah MM, Adkins NJ, Musker AJ, Roberts GT, et al. Development and testing of an additively manufactured monolithic catalyst bed for HTP thruster applications. Applied Catalysis A: General 2017;542:125-135.

(2) Galatas A, Hassanin H, Zweiri Y, Seneviratne L. Additive Manufactured Sandwich Composite/ABS Parts for Unmanned Aerial Vehicle Applications. Polymers 2018;10(11).

(3) Sabouri A, Yetisen AK, Sadigzade R, Hassanin H, Essa K, Butt H. Three-Dimensional Microstructured Lattices for Oil Sensing. Energy and Fuels 2017;31(3):2524-2529. 
(4) Mohammed A, Elshaer A, Sareh P, Elsayed M, Hassanin H. Additive Manufacturing Technologies for Drug Delivery Applications. Int J Pharm 2020;580.

(5) Zhang B, Gao L, Ma L, Luo Y, Yang H, Cui Z. 3D Bioprinting: A Novel Avenue for Manufacturing Tissues and Organs. Engineering 2019;5(4):777-794.

(6) Hassanin H, Finet L, Cox SC, Jamshidi P, Grover LM, Shepherd DET, et al. Tailoring selective laser melting process for titanium drug-delivering implants with releasing micro-channels. Additive Manufacturing 2018;20:144-155.

(7) Fina F, Goyanes A, Madla CM, Awad A, Trenfield SJ, Kuek JM, et al. 3D printing of drug-loaded gyroid lattices using selective laser sintering. Int J Pharm 2018;547(1-2):44-52.

(8) Goyanes A, Fina F, Martorana A, Sedough D, Gaisford S, Basit AW. Development of modified release 3D printed tablets (printlets) with pharmaceutical excipients using additive manufacturing. Int J Pharm 2017;527(1-2):21-30.

(9) Fina F, Madla CM, Goyanes A, Zhang J, Gaisford S, Basit AW. Fabricating 3D printed orally disintegrating printlets using selective laser sintering. Int J Pharm 2018;541(1-2):101-107.

(10) Khaled SA, Burley JC, Alexander MR, Roberts CJ. Desktop 3D printing of controlled release pharmaceutical bilayer tablets. International Journal of Pharmaceutics 2014;461(1):105-111.

(11) Liang K, Brambilla D, Leroux J. Is 3D Printing of Pharmaceuticals a Disruptor or Enabler? Advanced materials (Deerfield Beach, Fla.) 2019;31(5):e1805680.

(12) Klippstein H, Hassanin H, Alejandro, Diaz De Cerio Sanchez, Zweiri Y, Seneviratne L. Additive Manufacturing of Porous Structures for Unmanned Aerial Vehicles Applications. Adv Eng Mater 2018;20(9):1800290.

(13) Moritz T, Maleksaeedi S. 4 - Additive manufacturing of ceramic components. In: Zhang J, Jung Y, editors. Additive Manufacturing: Butterworth-Heinemann; 2018. p. 105-161.

(14) Qiu C, Adkins NJE, Hassanin H, Attallah MM, Essa K. In-situ shelling via selective laser melting: Modelling and microstructural characterisation. Mater Des 2015;87:845-853.

(15) Hassanin H, Essa K, Qiu C, Abdelhafeez AM, Adkins NJE, Attallah MM. Net-shape manufacturing using hybrid selective laser melting/hot isostatic pressing. Rapid Prototyping Journal 2017;23(4):720726.

(16) El-Sayed M, Hassanin H, Essa K. Bifilm defects and porosity in Al cast alloys. Int J Adv Manuf Technol 2016;86(5-8):1173-1179.

(17) Hassanin H, Alkendi Y, Elsayed M, Essa K, Zweiri Y. Controlling the Properties of Additively Manufactured Cellular Structures Using Machine Learning Approaches. Advanced Engineering Materials 2020;22(3):n/a. 
(18) Essa K, Khan R, Hassanin H, Attallah M, Reed R. An iterative approach of hot isostatic pressing tooling design for net-shape IN718 superalloy parts. Int J Adv Manuf Technol 2016;83(9-12):1835-1845.

(19) Kam D, Layani M, BarkaiMinerbi S, Orbaum D, Abrahami BenHarush S, Shoseyov O, et al. Additive Manufacturing of 3D Structures Composed of Wood Materials. Adv Mater Technol 2019;4(9):1900158.

(20) Melchels FPW, Domingos MAN, Klein TJ, Malda J, Bartolo PJ, Hutmacher DW. Additive manufacturing of tissues and organs. Progress in Polymer Science 2012;37(8):1079-1104.

(21) Mohammed Maniruzzaman, Wiley-VCH. 3D and 4D Printing in Biomedical Applications: Process Engineering and Additive Manufacturing. ; 2019.

(22) Al-Hashimi N, Begg N, Alany RG, Hassanin H, Elshaer A. Oral Modified Release Multiple-Unit Particulate Systems: Compressed Pellets, Microparticles and Nanoparticles. Pharmaceutics 2018;10(4).

(23) Brenan CJH. 3-D Printed Pills: A New Age for Drug Delivery. IEEE pulse 2015;6(5):3.

(24) Pravin S, Sudhir A. Integration of 3D printing with dosage forms: A new perspective for modern healthcare. Biomedicine \& Pharmacotherapy 2018;107:146-154.

(25) Kumar S. Selective laser sintering: A qualitative and objective approach. JOM 2003;55(10):43-47.

(26) Wang J, Goyanes A, Gaisford S, Basit AW. Stereolithographic (SLA) 3D printing of oral modifiedrelease dosage forms. Int J Pharm 2016;503(1-2):207-212.

(27) Skowyra J, Pietrzak K, Alhnan MA. Fabrication of extended-release patient-tailored prednisolone tablets via fused deposition modelling (FDM) 3D printing. European Journal of Pharmaceutical Sciences 2015;68:11-17.

(28) Wu BM, Borland SW, Giordano RA, Cima LG, Sachs EM, Cima MJ. Solid free-form fabrication of drug delivery devices. J Controlled Release 1996;40(1-2):77-87.

(29) Franco A, Lanzetta M, Romoli L. Experimental analysis of selective laser sintering of polyamide powders: an energy perspective. Journal of Cleaner Production 2010;18(16):1722-1730.

(30) Alhnan M, Okwuosa T, Sadia M, Wan K, Ahmed W, Arafat B. Emergence of 3D Printed Dosage Forms: Opportunities and Challenges. Pharm Res 2016;33(8):1817-1832.

(31) Fina F, Goyanes A, Gaisford S, Basit AW. Selective laser sintering (SLS) 3D printing of medicines. Int J Pharm 2017;529(1-2):285-293.

(32) Mazzoli A. Selective laser sintering in biomedical engineering. Medical and Biological Engineering and Computing 2012;51(3):1-12.

(33) Dickens E.D., Lin L.B., Taylor G.A., Magistro A.J. and Ng H. Sinterable Semi-Crystalline Powder and Near Fully Dense Article Formed Therewith . 1994 August 30,. 
(34) Kruth J-, Levy G, Klocke F, Childs THC. Consolidation phenomena in laser and powder-bed based layered manufacturing. CIRP Ann Manuf Technol 2007;56(2):730-759.

(35) Drummer D, Rietzel D, Kühnlein F. Development of a characterization approach for the sintering behavior of new thermoplastics for selective laser sintering. Physics Procedia 2010;5:533-542.

(36) Leong K, Chua C, Gui W, Verani W. Building Porous Biopolymeric Microstructures for Controlled Drug Delivery Devices Using Selective Laser Sintering. Int J Adv Manuf Technol 2006;31(5):483-489.

(37) Chia HN, Wu BM. Recent advances in 3D printing of biomaterials. Journal of biological engineering 2015;9(1):4.

(38) Norman J, Madurawe RD, Moore CMV, Khan MA, Khairuzzaman A. A new chapter in pharmaceutical manufacturing: 3D-printed drug products. Adv Drug Deliv Rev 2017;108:39-50.

(39) F.S. Iliescu. A double softlithography method for processing of noa63 microneedles arrays. UPB Scientific Bulletin, Series B: Chemistry and Materials Science 2017;79(2):121-132.

(40) Hassanin H, Jiang K. Multiple replication of thick PDMS micropatterns using surfactants as release agents. Microelectronic Engineering 2011;88(11):3275-3277.

(41) Zhu Z, Hassanin H, Jiang K. A soft moulding process for manufacture of net-shape ceramic microcomponents. Int J Adv Manuf Technol 2010;47(1):147-152.

(42) Hassanin H, Jiang K. Optimized process for the fabrication of zirconia micro parts. Microelectronic Engineering 2010;87(5):1617-1619.

(43) Hassanin H, Jiang K. Fabrication and characterization of stabilised zirconia micro parts via slip casting and soft moulding. Scr Mater 2013;69(6):433-436.

(44) Essa K, Modica F, Imbaby M, El-Sayed M, ElShaer A, Jiang K, et al. Manufacturing of metallic microcomponents using hybrid soft lithography and micro-electrical discharge machining. Int J Adv Manuf Technol 2017;91(1-4):445-452.

(45) Hassanin H, Jiang K. Fabrication of Al $2 \mathrm{O} 3$ /SiC Composite Microcomponents using Non-aqueous Suspension. Advanced Engineering Materials 2009;11(1):101-105.

(46) Hassanin H, Jiang K. Alumina composite suspension preparation for softlithography microfabrication. Microelectronic Engineering 2009;86(4):929-932.

(47) Hassanin H, Jiang K. Functionally graded microceramic components. Microelectronic Engineering 2010;87(5):1610-1613.

(48) Hassanin H, Jiang K. Net shape manufacturing of ceramic micro parts with tailored graded layers. J Micromech Microengineering 2013;24(1):015018. 
(49) Martinez PR, Goyanes A, Basit AW, Gaisford S. Fabrication of drug-loaded hydrogels with stereolithographic 3D printing. Int J Pharm 2017;532(1):313-317.

(50) Cavallo A, Madaghiele M, Masullo U, Lionetto MG, Sannino A. Photo-crosslinked poly(ethylene glycol) diacrylate (PEGDA) hydrogels from low molecular weight prepolymer: Swelling and permeation studies. J Appl Polym Sci 2017;134(2):n/a.

(51) Vehse M, Petersen S, Sternberg K, Schmitz K, Seitz H. Drug Delivery From Poly(ethylene glycol) Diacrylate Scaffolds Produced by DLC Based Micro-Stereolithography. Macromolecular Symposia 2014;346(1):43-47.

(52) Gittard SD, Narayan RJ. Laser direct writing of micro- and nano-scale medical devices. Expert Review of Medical Devices 2010;7(3):343-356.

(53) Goole J, Amighi K. 3D printing in pharmaceutics: A new tool for designing customized drug delivery systems. International Journal of Pharmaceutics 2016;499(1):376-394.

(54) Farkas B, Dante S, Brandi F. Photoinitiator-free 3D scaffolds fabricated by excimer laser photocuring. Nanotechnology 2016;28(3):034001.

(55) Applegate MB, Partlow BP, Coburn J, Marelli B, Pirie C, Pineda R, et al. Photocrosslinking of Silk Fibroin Using Riboflavin for Ocular Prostheses. Adv Mater 2016;28(12):2417-2420.

(56) Gonçalves F,A.M.M., Costa C, Fabela IGP, Farinha D, Faneca H, Simões P,N., et al. 3D printing of new biobased unsaturated polyesters by microstereo-thermal-lithography. Biofabrication 2014;6(3):035024.

(57) Applegate MB, Partlow BP, Coburn J, Marelli B, Pirie C, Pineda R, et al. Silk Fibroin:

Photocrosslinking of Silk Fibroin Using Riboflavin for Ocular Prostheses (Adv. Mater. 12/2016. Adv Mater 2016;28(12):2464.

(58) Miao S, Zhu W, Castro NJ, Nowicki M, Zhou X, Cui H, et al. 4D printing smart biomedical scaffolds with novel soybean oil epoxidized acrylate. Sci Rep 2016;6(1):27226.

(59) Martinez PR, Goyanes A, Basit AW, Gaisford S. Influence of Geometry on the Drug Release Profiles of Stereolithographic (SLA) 3D-Printed Tablets. AAPS PharmSciTech 2018;19(8):3355.

(60) Robles-Martinez P, Xu X, Trenfield SJ, Awad A, Goyanes A, Telford R, et al. 3D printing of a multilayered polypill containing six drugs using a novel stereolithographic method. Pharmaceutics 2019;11(6).

(61) Xu X, Robles-Martinez P, Madla CM, Joubert F, Goyanes A, Basit AW, et al. Stereolithography (SLA) 3D printing of an antihypertensive polyprintlet: Case study of an unexpected photopolymer-drug reaction. Additive Manufacturing 2020;33:101071.

(62) Tan DK, Maniruzzaman M, Nokhodchi A. Advanced Pharmaceutical Applications of Hot-Melt Extrusion Coupled with Fused Deposition Modelling (FDM) 3D Printing for Personalised Drug Delivery. Pharmaceutics 2018;10(4). 
(63) Kempin W, Domsta V, Grathoff G, Brecht I, Semmling B, Tillmann S, et al. Immediate Release 3DPrinted Tablets Produced Via Fused Deposition Modeling of a Thermo-Sensitive Drug. Pharm Res 2018;35(6):1-12.

(64) Goyanes A, Buanz ABM, Hatton GB, Gaisford S, Basit AW. 3D printing of modified-release aminosalicylate (4-ASA and 5-ASA) tablets. European Journal of Pharmaceutics and Biopharmaceutics 2015;89:157-162.

(65) Smith DM, Kapoor Y, Klinzing GR, Procopio AT. Pharmaceutical 3D printing: Design and qualification of a single step print and fill capsule. Int J Pharm 2018;544(1):21-30.

(66) Goyanes A, Robles Martinez P, Buanz A, Basit AW, Gaisford S. Effect of geometry on drug release from 3D printed tablets. Int J Pharm 2015;494(2):657-663.

(67) Goyanes A, Wang J, Buanz A, Martínez-Pacheco R, Telford R, Gaisford S, et al. 3D Printing of Medicines: Engineering Novel Oral Devices with Unique Design and Drug Release Characteristics. Molecular pharmaceutics 2015;12(11):4077-4084.

(68) Holländer J, Genina N, Jukarainen H, Khajeheian M, Rosling A, Mäkilä E, et al. Three-Dimensional Printed PCL-Based Implantable Prototypes of Medical Devices for Controlled Drug Delivery. J Pharm Sci 2016;105(9):2665-2676.

(69) Gioumouxouzis Cl, Baklavaridis A, Katsamenis OL, Markopoulou CK, Bouropoulos N, Tzetzis D, et al. A 3D printed bilayer oral solid dosage form combining metformin for prolonged and glimepiride for immediate drug delivery. European Journal of Pharmaceutical Sciences 2018;120:40-52.

(70) Farah S, Anderson DG, Langer R. Physical and mechanical properties of PLA, and their functions in widespread applications - A comprehensive review. Advanced Drug Delivery Reviews 2016;107:367392.

(71) Eda HB, Yildirim Erbil H. Surface Modification of 3D Printed PLA Objects by Fused Deposition Modeling: A Review. Colloids and Interfaces 2019;3(2):43.

(72) Garlotta D. A literature review of poly(lactic acid). Journal of Polymers and the Environment 2001;9(2):63-84.

(73) Tokiwa Y, Calabia B. Biodegradability and biodegradation of poly(lactide). Appl Microbiol Biotechnol 2006;72(2):244-251.

(74) Demerlis CC, Schoneker DR. Review of the oral toxicity of polyvinyl alcohol (PVA). Food and Chemical Toxicology 2003;41(3):319-326.

(75) Gaaz T, Sulong AB, Akhtar M, Kadhum A, Mohamad AB, Al-Amiery AA. Properties and Applications of Polyvinyl Alcohol, Halloysite Nanotubes and Their Nanocomposites. Molecules 2015;20(12):2283322847. 
(76) MatterHackers. How To Succeed When 3D Printing With PVA Support Material. 2017; Available at: https://www.matterhackers.com/news/how-to-succeed-when-3d-printing-with-pva-support-material. Accessed March 2, 2020.

(77) Pietrzak K, Isreb A, Alhnan MA. A flexible-dose dispenser for immediate and extended release 3D printed tablets. European Journal of Pharmaceutics and Biopharmaceutics 2015;96:380-387.

(78) Melocchi A, Parietti F, Maroni A, Foppoli A, Gazzaniga A, Zema L. Hot-melt extruded filaments based on pharmaceutical grade polymers for 3D printing by fused deposition modeling. Int J Pharm 2016;509(1-2):255-263.

(79) Alhijjaj M, Belton P, Qi S. An investigation into the use of polymer blends to improve the printability of and regulate drug release from pharmaceutical solid dispersions prepared via fused deposition modeling (FDM) 3D printing. European Journal of Pharmaceutics and Biopharmaceutics 2016;108:111125.

(80) Zhang J, Feng X, Patil H, Tiwari RV, Repka MA. Coupling 3D printing with hot-melt extrusion to produce controlled-release tablets. Int J Pharm 2017;519(1-2):186-197.

(81) Jamróz W, Szafraniec J, Kurek M, Jachowicz R. 3D Printing in Pharmaceutical and Medical Applications - Recent Achievements and Challenges. Pharm Res 2018;35(9):1-22.

(82) Goyanes A, Buanz ABM, Basit AW, Gaisford S. Fused-filament 3D printing (3DP) for fabrication of tablets. Int J Pharm 2014;476(1-2):88-92.

(83) Goyanes A, Chang H, Sedough D, Hatton GB, Wang J, Buanz A, et al. Fabrication of controlledrelease budesonide tablets via desktop (FDM) 3D printing. Int J Pharm 2015;496(2):414-420.

(84) Okwuosa TC, Stefaniak D, Arafat B, Isreb A, Wan K, Alhnan MA. A Lower Temperature FDM 3D Printing for the Manufacture of Patient-Specific Immediate Release Tablets. Pharm Res 2016;33(11):2704-2712.

(85) Goyanes A, Kobayashi M, Martínez-Pacheco R, Gaisford S, Basit AW. Fused-filament 3D printing of drug products: Microstructure analysis and drug release characteristics of PVA-based caplets. Int J Pharm 2016;514(1):290-295.

(86) Sadia M, Sośnicka A, Arafat B, Isreb A, Ahmed W, Kelarakis A, et al. Adaptation of pharmaceutical excipients to FDM 3D printing for the fabrication of patient-tailored immediate release tablets. Int J Pharm 2016;513(1-2):659-668.

(87) Nasereddin J, Wellner N, Alhijjaj M, Belton P, Qi S. Development of a Simple Mechanical Screening Method for Predicting the Feedability of a Pharmaceutical FDM 3D Printing Filament. Pharm Res 2018;35(8):1-13.

(88) Chai X, Chai H, Wang X, Yang J, Li J, Zhao Y, et al. Fused Deposition Modeling (FDM) 3D Printed Tablets for Intragastric Floating Delivery of Domperidone. Sci Rep 2017;7(1):2829. 
(89) GBI Research. Oral Drug Delivery Market Report. 2012; Available at:

https://www.contractpharma.com/issues/2012-06/view features/oral-drug-delivery-market-report/.

Accessed February 14, 2020.

(90) Sadia M, Arafat B, Ahmed W, Forbes RT, Alhnan MA. Channelled tablets: An innovative approach to accelerating drug release from 3D printed tablets. J Controlled Release 2018;269:355-363.

(91) Scoutaris N, Ross S, Douroumis D. Current Trends on Medical and Pharmaceutical Applications of Inkjet Printing Technology. Pharm Res 2016;33(8):1799-1816.

(92) Derby B. Additive Manufacture of Ceramics Components by Inkjet Printing. Engineering 2015;1(1):113-123.

(93) Scoutaris N, Alexander MR, Gellert PR, Roberts CJ. Inkjet printing as a novel medicine formulation technique. J Controlled Release 2011;156(2):179-185.

(94) Rose D. Microdispensing technologies in drug discovery. Drug Discov Today 1999;4(9):411-419.

(95) Gbureck U, Hölzel T, Doillon C, Müller F , Barralet J . Direct Printing of Bioceramic Implants with Spatially Localized Angiogenic Factors. Adv Mater 2007;19(6):795-800.

(96) Arrabito G, Pignataro B. Inkjet printing methodologies for drug screening. Anal Chem 2010;82(8):3104-3107.

(97) Walter G, Büssow K, Cahill D, Lueking A, Lehrach H. Protein arrays for gene expression and molecular interaction screening. Curr Opin Microbiol 2000;3(3):298-302.

(98) Boehm RD, Miller PR, Daniels J, Stafslien S, Narayan RJ. Inkjet printing for pharmaceutical applications. Materials Today 2014;17(5):247-252.

(99) Kulkarni RB, Manners C, inventors. 3D Systems, Inc. (Valencia, CA), assignee. Rapid prototyping method and apparatus with simplified build preparation for production of three dimensional objects. . 2000 December 12,.

(100) WIGAND J, Theodore, WINEY, Calvin, McCoy, III, ARANKA M, inventors. SOLIDSCAPE INC, assignee. Method and apparatus for fabricating three dimensional models. WIPO (PCT) patent WO 2007/016469 A2. 2007 February 8.

(101) Sachs, Emanuel M, Haggerty, John S, Cima, Michael J, et al, inventors. Massachusetts Institute of Technology, assignee. Three-dimensional printing techniques. United States patent 5,204,055. 1993 Apr. 20 .

(102) Katstra WE, Palazzolo RD, Rowe CW, Giritlioglu B, Teung P, Cima MJ. Oral dosage forms fabricated by Three Dimensional Printingâ,, c. Journal of Controlled Release 2000;66(1):1-9.

(103) Rowe CW, Katstra WE, Palazzolo RD, Giritlioglu B, Teung P, Cima MJ. Multimechanism oral dosage forms fabricated by three dimensional printing ${ }^{\mathrm{TM}}$. J Controlled Release 2000;66(1):11-17. 
(104) Yu D, Branford-White C, Yang Y, Zhu L, Welbeck EW, Yang X. A novel fast disintegrating tablet fabricated by three-dimensional printing. Drug Dev Ind Pharm 2009;35(12):1530-1536.

(105) Clark EA, Alexander MR, Irvine DJ, Roberts CJ, Wallace MJ, Sharpe S, et al. 3D printing of tablets using inkjet with UV photoinitiation. Int J Pharm 2017;529(1-2):523-530.

(106) Khaled SA, Burley JC, Alexander MR, Yang J, Roberts CJ. 3D printing of five-in-one dose combination polypill with defined immediate and sustained release profiles. J Controlled Release 2015;217:308-314.

(107) Tagami T, Fukushige K, Ogawa E, Hayashi N, Ozeki T. 3D Printing Factors Important for the Fabrication of Polyvinylalcohol Filament-Based Tablets. Biological and Pharmaceutical Bulletin 2017;40(3):357-364.

(108) Melocchi A, Uboldi M, Maroni A, Foppoli A, Palugan L, Zema L, et al. 3D printing by fused deposition modeling of single- and multi-compartment hollow systems for oral delivery - A review. International Journal of Pharmaceutics 2020;579:119155.

(109) Huanbutta K, Sangnim T. Design and development of zero-order drug release gastroretentive floating tablets fabricated by 3D printing technology. Journal of Drug Delivery Science and Technology 2019;52:831-837.

(110) Redekop WK, Mladsi D. The Faces of Personalized Medicine: A Framework for Understanding Its Meaning and Scope. Value in Health 2013;16(6):S4-S9.

(111) Rollason V, Vogt N. Reduction of Polypharmacy in the Elderly. Drugs Aging 2003;20(11):817-832.

(112) Maher RL, Hanlon J, Hajjar ER. Clinical consequences of polypharmacy in elderly. Expert Opinion on Drug Safety 2014;13(1):57-65.

(113) Hajjar ER, Cafiero AC, Hanlon JT. Polypharmacy in elderly patients. The American Journal of Geriatric Pharmacotherapy 2007;5(4):345-351.

(114) Colley CA, Lucas LM. Polypharmacy: the cure becomes the disease. Journal of general internal medicine 1993;8(5):278-283.

(115) Vik SA, Maxwell CJ, Hogan DB. Measurement, correlates, and health outcomes of medication adherence among seniors. Ann Pharmacother 2004;38(2):303-312.

(116) Lee VW, Pang KK, Hui KC, Kwok JC, Leung SL, Yu DSF, et al. Medication adherence: Is it a hidden drug-related problem in hidden elderly? Geriatrics and Gerontology International 2013;13(4).

(117) Richard Matthews. Proposed new regulations for 3D printed medical devices must go further. 2018; Available at: https://theconversation.com/proposed-new-regulations-for-3d-printed-medicaldevices-must-go-further-90314. Accessed February 14, 2020. 
(118) Drues Michael. Printing medical devices at home is just the beginning: Part II. 2014; Available at: https://www.healthcarepackaging.com/machinery-materials/package-design/blog/13287919/printingmedical-devices-at-home-is-just-the-beginning-part-ii. Accessed February 14., 2020.

(119) Trenfield SJ, Goyanes A, Telford R, Wilsdon D, Rowland M, Gaisford S, et al. 3D printed drug products: Non-destructive dose verification using a rapid point-and-shoot approach. International Journal of Pharmaceutics 2018;549(1):283-292.

(120) Vakili H, Kolakovic R, Genina N, Marmion M, Salo H, Ihalainen P, et al. Hyperspectral imaging in quality control of inkjet printed personalised dosage forms. International Journal of Pharmaceutics 2015;483(1):244-249. 